\title{
A SIMPLE AND UNIFIED THREE-DIMENSIONAL MODEL TO DESCRIBE VARIOUS CHARACTERISTICS OF SOILS
}

\author{
Teruo Nakai ${ }^{\mathrm{i}}$, Hossain Md. Shahin ${ }^{\mathrm{ii} i}$, Mamoru Kikumoto ${ }^{\mathrm{iii}}$, \\ Hiroyuki Kyokawa ${ }^{\text {iv) }}$, Feng Zhang ${ }^{\text {v) }}$ and Marcio M. FARIaS ${ }^{\text {vi) }}$
}

\begin{abstract}
A simple and unified model to describe some features of soil behavior in one dimensional condition is presented in another related paper (Nakai et al., 2011). In the present paper, this one-dimensional model is extended to describe not only the soil features explained in the related paper three-dimensionally (3D), but also to explain other soil features found in multi-dimensional conditions, such as shear behavior considering the influence of intermediate principal stress on the deformation and strength of soils, and the positive and negative soil dilatancy. Firstly, the first step in extending any kind of one-dimensional model to a three-dimensional one is explained in detail: the significance of $t_{\mathrm{ij}}$ concept and its stress invariants $\left(t_{\mathrm{N}}\right.$ and $\left.t_{\mathrm{S}}\right)$ is explained and compared with the idea of ordinary stress invariants $(p$ and $q)$ used in the Cam clay model. Then, the advanced elastoplastic relations (stages I to III) in the one-dimensional condition presented in the related paper are re-formulated as three-dimensional models-e.g., a model for over consolidated soil, a model for structured soil and a model which considers time-dependent behavior. The three-dimensional models for over consolidated soil (stage I) and structured soil (stage II) are formulated so as to coincide with the subloading $t_{\mathrm{ij}}$ model developed by Nakai and Hinokio (2004) and by Nakai (2007), respectively. The validity of the models in stage I and stage II is checked by simulations of various shear tests for sands with different void ratios and for over consolidated and natural clays under drained and undrained conditions. The model in stage III is verified by simulations of shear tests with different strain rates, and by simulating creep tests and others, not only for normally consolidated clay but also for non-structured and structured over consolidated clays under drained and undrained conditions.
\end{abstract}

Key words: bonding, clay, constitutive equation of soil, creep, deformation, density, elastoplasticity, (intermediate principal stress), over consolidated soil, rheology, sand, shear, strength, structured soil, three-dimensional condition, time-dependent behavior (IGC: D5/D6)

\section{INTRODUCTION}

As stated in another related paper (Nakai et al., 2011), the following important features of soil behavior cannot be described by the Cam clay model (e.g., Schofield and Wroth, 1968).

(1) Influence of the intermediate principal stress on the deformation and strength of geomaterials;

(2) Stress path dependency of the direction of plastic flow;

(3) Positive dilatancy during strain hardening;

(4) Stress induced anisotropy and cyclic loading;

(5) Inherent anisotropy;

(6) Influence of density and/or confining pressure on the deformation and strength;

(7) Behavior of structured soils such as naturally deposited clays;

(8) Time-dependent behavior and rheological characteristics;

(9) Temperature-dependent behavior;

(10) Behavior of unsaturated soils;

(11) Influence of particle crushing.

The method to take into consideration features (6) to (8) was explained in the related paper for one-dimensional models. Further, features (9) to (11) also can be described by using more or less the same procedure adopted to include features (6) to (8). On the other hand, features (1) to (5) can be observed only in multi-dimensional conditions.

The Geotechnical group of Nagoya Institute of Technology (NIT) developed three-dimensional elastoplastic models for soils that can describe features (1) to (3)-e.g.,

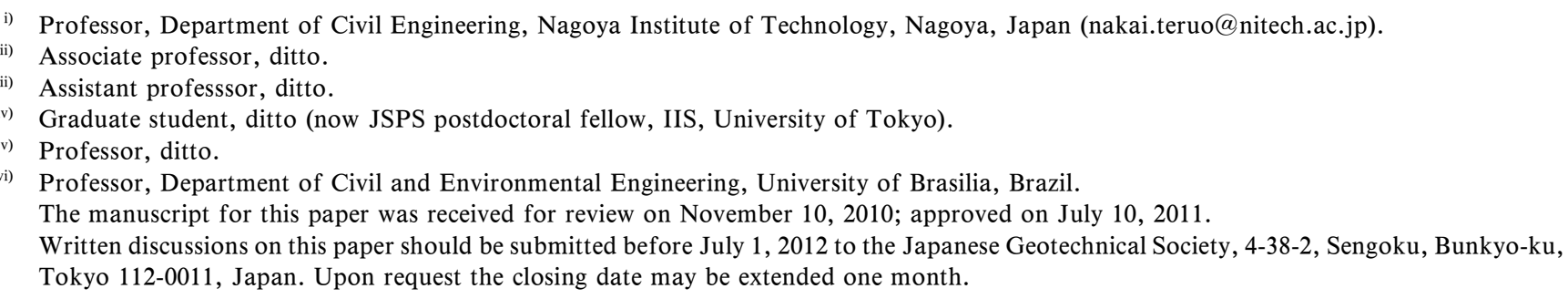


$t_{\mathrm{ij}}$-clay model (Nakai and Matsuoka, 1986), $t_{\mathrm{ij}}$-sand model (Nakai, 1989) and subloading $t_{\mathrm{ij}}$ model (Nakai and Hinokio, 2004). These models are particularly good at dealing with feature "(1) the influence of intermediate principal stress on the deformation and strength' using $t_{\mathrm{ij}}$ concept (Nakai and Mihara, 1984). In the present paper, the meaning of the $t_{\mathrm{ij}}$ concept is explained simply by comparing it with the ordinary stress concept used in the Cam clay model and many other models. Also a straightforward way for extending one-dimensional models to threedimensional ones is indicated. Then, an extension of the one-dimensional elastoplastic models, which can describe features (6) to (8), is shown. The validity of the present models is confirmed by the simulations of various kinds of drained and undrained shear tests on normally consolidated soil, over consolidated soil and structured soil under general stress conditions.

\section{OUTLINE OF THREE-DIMENSIONAL EXTENSION BASED ON AN ORDINARY CONCEPT}

\section{Cam Clay Model and Its Stress and Strain Increment Invariants}

Most of the constitutive models for soils, like the Cam clay model (Schofield and Wroth, 1968; Roscoe and Burland, 1968), have been formulated using stress invariants such as the mean stress $p$ and the deviatoric stress $q$ and the correspondent strain increment invariants like the volumetric strain increment $d \varepsilon_{\mathrm{v}}$ and the deviatoric strain increment $d \varepsilon_{\mathrm{d}}$. These invariants are defined by the normal and parallel components of the stress and the strain increments with respect to the octahedral plane (see Figs. 1 and 2) and their expression is given by Eqs. (1) to (4):

$$
\begin{aligned}
p & =\sqrt{\frac{1}{3}} \overline{\mathrm{ON}}=\frac{1}{3}\left(\sigma_{1}+\sigma_{2}+\sigma_{3}\right)=\frac{1}{3} \sigma_{\mathrm{ij}} \delta_{\mathrm{ij}} \\
q & =\sqrt{\frac{3}{2}} \overline{\mathrm{NP}}=\frac{1}{\sqrt{2}} \sqrt{\left(\sigma_{1}-\sigma_{2}\right)^{2}+\left(\sigma_{2}-\sigma_{3}\right)^{2}+\left(\sigma_{3}-\sigma_{1}\right)^{2}} \\
d \varepsilon_{\mathrm{v}} & =\sqrt{3} \overline{\mathrm{O}^{\prime} \mathrm{N}^{\prime}}=d \varepsilon_{1}+d \varepsilon_{2}+d \varepsilon_{3}=d \varepsilon_{\mathrm{ij}} \delta_{\mathrm{ij}} \\
d \varepsilon_{\mathrm{d}} & =\sqrt{\frac{2}{3}} \overline{\mathrm{N}^{\prime} \mathrm{P}^{\prime}} \\
& =\frac{\sqrt{2}}{3} \sqrt{\left(d \varepsilon_{1}-d \varepsilon_{2}\right)^{2}+\left(d \varepsilon_{2}-d \varepsilon_{3}\right)^{2}+\left(d \varepsilon_{3}-d \varepsilon_{1}\right)^{2}} \\
& =\sqrt{\frac{2}{3}\left(d \varepsilon_{\mathrm{ij}}-\frac{d \varepsilon_{\mathrm{v}}}{3} \delta_{\mathrm{ij}}\right)\left(d \varepsilon_{\mathrm{ij}}-\frac{d \varepsilon_{\mathrm{v}}}{3} \delta_{\mathrm{ij}}\right)}
\end{aligned}
$$

Here, $\sigma_{1}, \sigma_{2}$ and $\sigma_{3}$ are the three principal stresses, $\sigma_{\mathrm{ij}}$ is the stress tensor, $\delta_{\mathrm{ij}}$ is the unit tensor, $d \varepsilon_{1}, d \varepsilon_{2}$ and $d \varepsilon_{3}$ are the three principal strain increments, and $d \varepsilon_{\mathrm{ij}}$ is the strain increment tensor.

Figure 3 shows the yield surfaces of an ordinary elastoplastic model, such as the Cam clay model, represented on the $p-q$ plane. The broken curve and solid curve indicate the initial and current yield surfaces when the stress condition moves from the initial state I to the

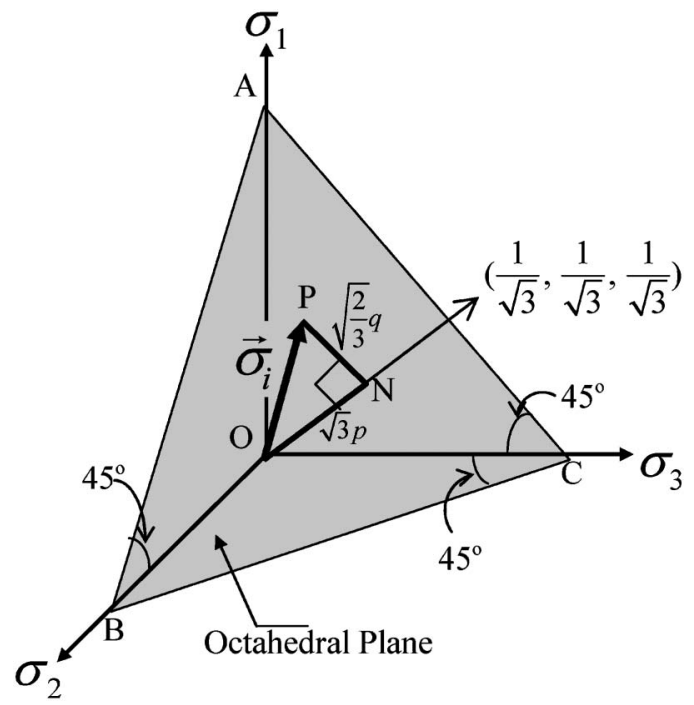

Fig. 1. Definitions of $p$ and $q$

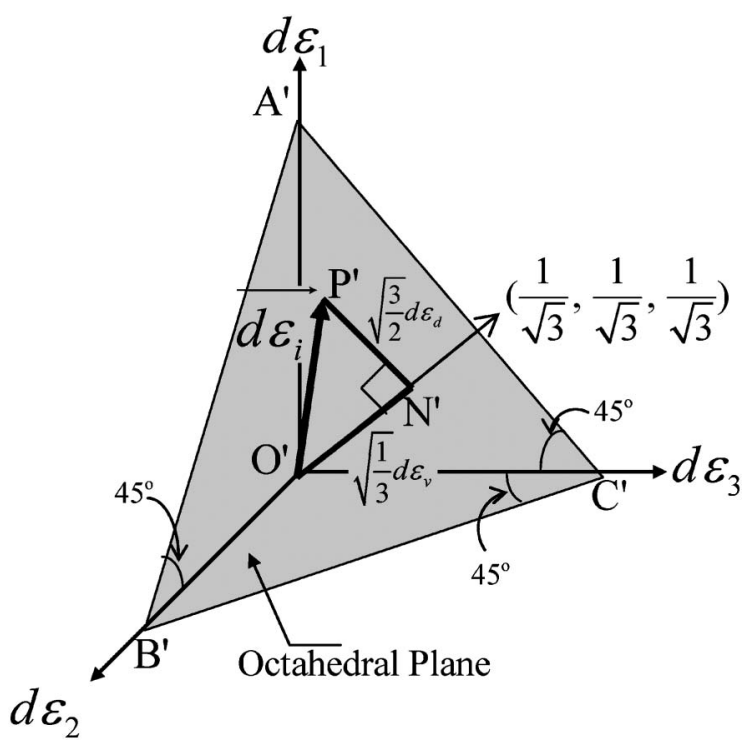

Fig. 2. Definitions of $d \varepsilon_{\mathrm{v}}$ and $d \varepsilon_{\mathrm{d}}$

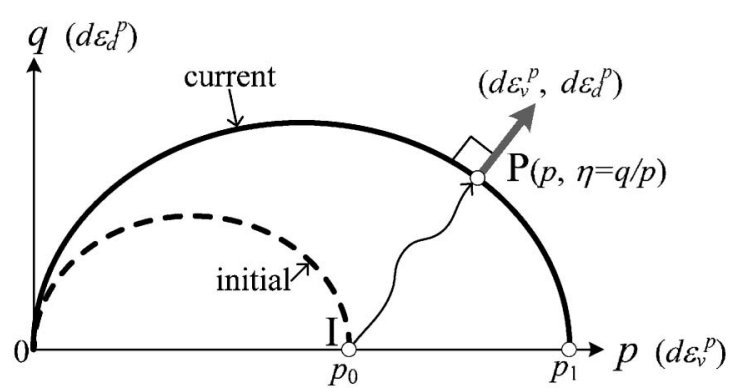

Fig. 3. Initial and current yield surfaces in the $p-q$ plane and direction of plastic flow in an ordinary model such as Cam clay model

current state $\mathrm{P}$ with elastoplastic deformation. Here, $p_{0}$ and $p_{1}$ are the values of $p$ on $p$-axis for the initial and current yield surfaces, respectively, which determine the size of these surfaces. The yield surface (yield function) in 


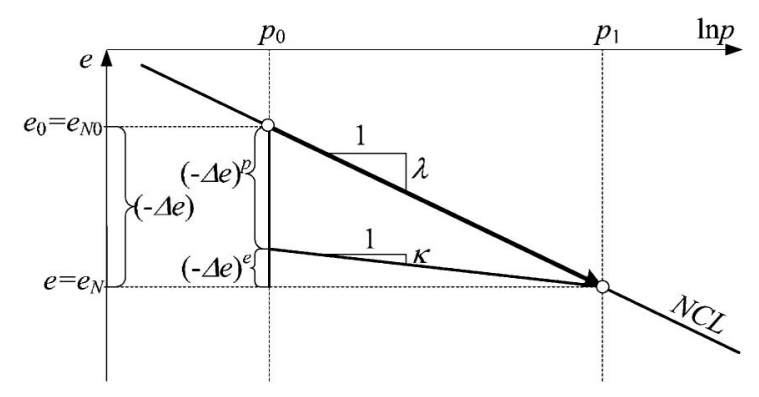

Fig. 4. Change of void ratio in isotropic compression from $p=p_{0}$ to $p$ $=p_{1}$ in normally consolidated soils

most of the ordinary elastoplastic models, such as illustrated by the solid curve in Fig. 3, is represented by a function of the mean stress $p$ and the stress ratio $\eta$ in the following form:

$$
\begin{array}{r}
\ln p+\varsigma(\eta)-\ln p_{1}=\ln \frac{p}{p_{0}}+\varsigma(\eta)-\ln \frac{p_{1}}{p_{0}}=0 \\
(\text { where } \eta=q / p)
\end{array}
$$

where, $\zeta(\eta)$ is an increasing function of $\eta$ which satisfies the condition $\zeta(0)=0$. For example, the stress ratio function $\zeta(\eta)$ is given as follows for the original Cam-clay model (Schofield and Wroth, 1968) and the modified Cam-clay model (Roscoe and Burland, 1968):

$$
\begin{array}{ll}
\varsigma(\eta)=\frac{1}{\mathrm{M}} \eta & \text { (original) } \\
\varsigma(\eta)=\ln \frac{\mathrm{M}^{2}+\eta^{2}}{\mathrm{M}^{2}} & \text { (modified) }
\end{array}
$$

where, $\mathrm{M}$ is the stress ratio $\eta$ at the critical state.

Now, in the Cam clay model, the size of yield surface is related to the plastic change in void ratio $(-\Delta e)^{\mathrm{p}}$ or the plastic volumetric strain $\varepsilon_{\mathrm{v}}^{\mathrm{p}}$. When a normally consolidated soil is compressed isotropically from $p=p_{0}$ to $p=p_{1}$, the void ratio changes from $e_{\mathrm{N} 0}$ to $e_{\mathrm{N}}$ on the normal consolidation line (NCL) as shown in Fig. 4. Then, the plastic change of void ratio or plastic volumetric strain can be expressed as:

$$
\left.\begin{array}{rl}
(-\Delta e)^{\mathrm{p}} & =\left(e_{0}-e\right)-(-\Delta e)^{\mathrm{e}}=\left(e_{\mathrm{NO}}-e_{\mathrm{N}}\right)-(-\Delta e)^{\mathrm{e}} \\
& =(-\Delta e)-(-\Delta e)^{\mathrm{e}}=(\lambda-\kappa) \ln \frac{p_{1}}{p_{0}} \\
& \text { or } \\
& \varepsilon_{\mathrm{v}}^{\mathrm{p}}=\frac{(-\Delta e)^{\mathrm{p}}}{1+e_{0}}=\frac{\lambda-\kappa}{1+e_{0}} \ln \frac{p_{1}}{p_{0}}
\end{array}\right\}
$$

Here, $\lambda$ and $\kappa$ denote compression index and swelling index, and $e_{0}$ and $e$ are void ratio at $p=p_{0}$ and $p=p_{1}$. Throughout this paper, superscripts $p$ and $e$ imply the plastic and elastic components of the quantities, respectively. From Eqs. (5) and (8), the well-known yield function of Cam clay model is obtained:

$$
\begin{aligned}
& (\lambda-\kappa)\left\{\ln \frac{p}{p_{0}}+\varsigma(\eta)\right\}-(-\Delta e)^{\mathrm{p}}=0 \quad \text { or } \\
& \frac{\lambda-\kappa}{1+e_{0}}\left\{\ln \frac{p}{p_{0}}+\varsigma(\eta)\right\}-\varepsilon_{\mathrm{v}}^{\mathrm{p}}=0
\end{aligned}
$$

Equation (9) may be rewritten as:

$$
F=H \quad \text { or } \quad f=F-H=0
$$

Here, $F$ and $H$ denote the term related to stress change and the term related the plastic change in void ratio, respectively, as follows:

$$
\begin{aligned}
& F=(\lambda-\kappa) \ln \frac{p_{1}}{p_{0}}=(\lambda-\kappa)\left\{\begin{array}{l}
\ln \frac{p}{p_{0}}+\varsigma(\eta) \\
(\text { where } \eta=q
\end{array}\right\} \\
& H=(-\Delta e)^{\mathrm{p}}=\left(1+e_{0}\right) \cdot \varepsilon_{\mathrm{v}}^{\mathrm{p}}
\end{aligned}
$$

Comparing Eqs. (10) to (12) with the corresponding equations in the one-dimensional model described in the related paper (Nakai et al., 2011), it can be seen that the yield function of the Cam clay model is easily obtained simply by replacing $\sigma_{0}$ and $\sigma$ in the function $F$ of the onedimensional model by the mean quantities $p_{0}$ and $p_{1}$ in three-dimensional conditions as shown in Eq. (11).

The plastic strain increment can be calculated by assuming an associated flow rule in the ordinary stress space (see Fig. 3), thus obtaining:

$$
d \varepsilon_{\mathrm{ij}}^{\mathrm{p}}=\Lambda \frac{\partial F}{\partial \sigma_{\mathrm{ij}}}=\Lambda\left(\frac{\partial F}{\partial p} \frac{\partial p}{\partial \sigma_{\mathrm{ij}}}+\frac{\partial F}{\partial \eta} \frac{\partial \eta}{\partial \sigma_{\mathrm{ij}}}\right)
$$

From the consistency condition $(d f=0)$, the proportionality constant $\Lambda$ is given by

$$
\Lambda=\frac{d F}{\left(1+e_{0}\right) \frac{\partial F}{\partial \sigma_{\mathrm{kk}}}}=\frac{d F}{h^{\mathrm{p}}} \quad\left(\text { where } d F=\frac{\partial F}{\partial \sigma_{\mathrm{ij}}} d \sigma_{\mathrm{ij}}\right)
$$

Here, $h^{\text {p }}$ represents a plastic modulus. From Eqs. (11) and (13), the following relation between stress ratio and plastic strain increment ratio (stress-dilatancy relation) is obtained:

$$
\frac{d \varepsilon_{\mathrm{v}}^{\mathrm{p}}}{d \varepsilon_{\mathrm{d}}^{\mathrm{p}}}=\frac{\frac{\partial F}{\partial p}+\frac{\partial F}{\partial \eta} \frac{\partial \eta}{\partial p}}{\frac{\partial F}{\partial \eta} \frac{\partial \eta}{\partial q}}=\frac{1-\zeta^{\prime}(\eta) \cdot \eta}{\zeta^{\prime}(\eta)}
$$

where $\zeta^{\prime}(\eta)$ means $d \zeta(\eta) / d \eta$. The stress-dilatancy relation for the original and modified Cam clay models are expressed as follows, from Eqs. (6), (7) and (15):

$$
\begin{array}{ll}
\frac{d \varepsilon_{\mathrm{v}}^{\mathrm{p}}}{d \varepsilon_{\mathrm{d}}^{\mathrm{p}}}=\mathrm{M}-\eta & \text { (original) } \\
\frac{d \varepsilon_{\mathrm{v}}^{\mathrm{p}}}{d \varepsilon_{\mathrm{d}}^{\mathrm{p}}}=\frac{\mathrm{M}^{2}-\eta^{2}}{2 \eta} & \text { (modified) }
\end{array}
$$

The shape of the yield surfaces for the two models in the $p-q$ plane and the direction of plastic strain increments are shown in Fig. 5, and the stress-dilatancy relation for the two models are shown in Fig. 6. Also, the shapes of yield surfaces which are formulated using $p$ and $q$ are inevitably circular on the octahedral plane, and therefore the direction of plastic strain increments on the octahedral plane is always in the radial direction as shown in Fig. 7.

The elastic strain increment is given by the generalized Hooke's law: 

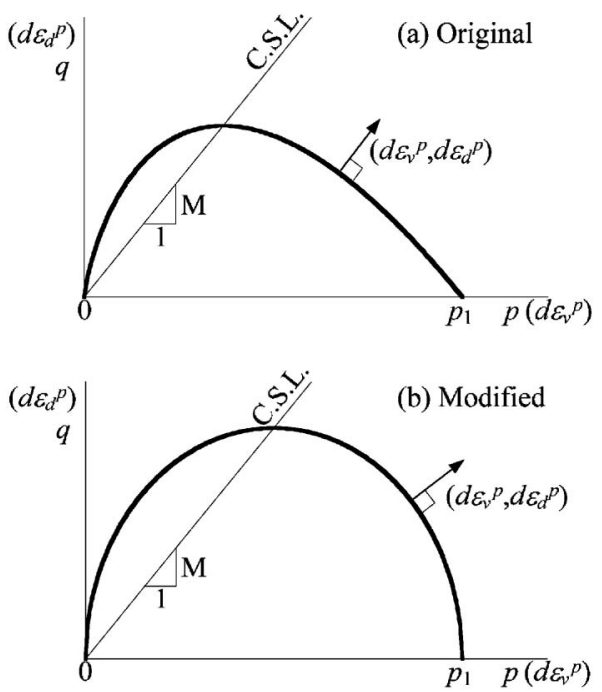

Fig. 5. Yield surface of Cam clay model on the $p-q$ plane
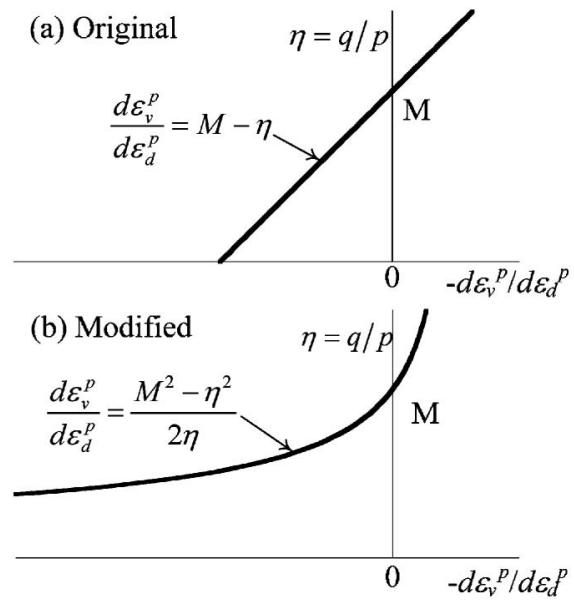

Fig. 6. Stress-dilatancy relation of the Cam clay model

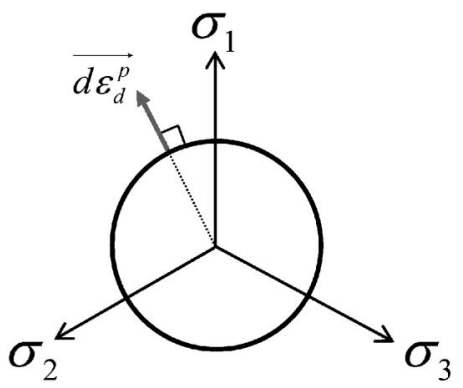

Fig. 7. Yield surface of the Cam clay model and direction of plastic flow on the octahedral plane

$$
d \varepsilon_{\mathrm{ij}}^{\mathrm{e}}=\frac{1+v_{\mathrm{e}}}{E_{\mathrm{e}}} d \sigma_{\mathrm{ij}}-\frac{v_{\mathrm{e}}}{E_{\mathrm{e}}} d \sigma_{\mathrm{kk}} \delta_{\mathrm{ij}}
$$

The Young's modulus $E_{\mathrm{e}}$ is expressed in terms of the swelling index $\kappa$ and the Poisson's ratio $v_{\mathrm{e}}$ as:

$$
E_{\mathrm{e}}=\frac{3\left(1-2 v_{\mathrm{e}}\right)\left(1+e_{0}\right) p}{\kappa}
$$

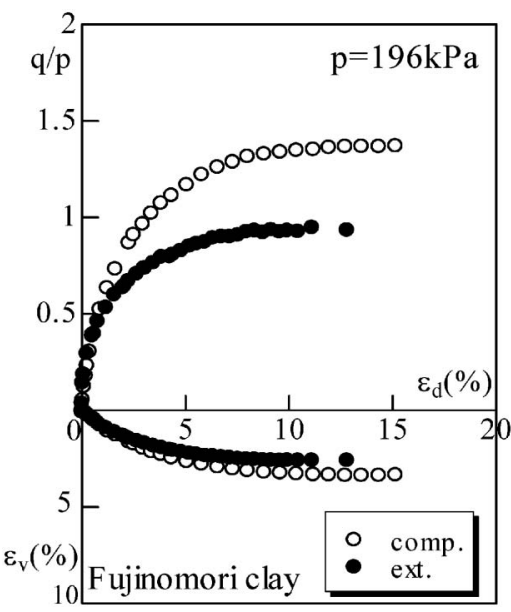

Fig. 8. Observed stress-strain relation of drained triaxial compression and extension tests on normally consolidated clay

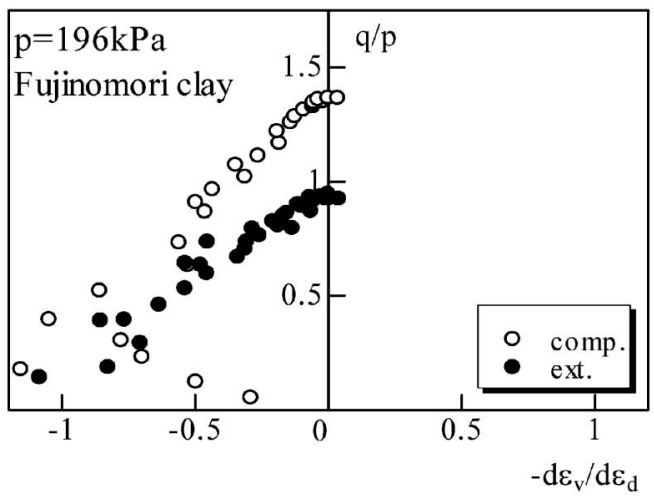

Fig. 9. $q / p: d \varepsilon_{\mathrm{v}} / d \varepsilon_{\mathrm{d}}$ relation for drained triaxial compression and extension tests on a normally consolidated clay

Therefore, the total strain increment is given by:

$$
d \varepsilon_{\mathrm{ij}}^{\mathrm{e}}=d \varepsilon_{\mathrm{ij}}^{\mathrm{e}}+d \varepsilon_{\mathrm{ij}}^{\mathrm{p}}
$$

The loading condition of a usual elastoplastic models is expressed as follows:

$$
\begin{cases}d \varepsilon_{\mathrm{ij}}^{\mathrm{p}} \neq 0 & \text { if } f=0 \text { and } d F>0 \\ d \varepsilon_{\mathrm{ij}}^{\mathrm{p}}=0 & \text { otherwise }\end{cases}
$$

The yield surface is fixed when no plastic strain occurs.

\section{Consideration of Three-dimensional Stress-strain Behav- ior of Soils}

Figure 8 shows the observed results of drained triaxial compression $\left(\sigma_{1}>\sigma_{2}=\sigma_{3}\right)$ and triaxial extension $\left(\sigma_{1}=\sigma_{2}\right.$ $>\sigma_{3}$ ) tests on normally consolidated Fujinomori clay under constant mean principal stress $(p=196 \mathrm{kPa})$, in terms of the relation between stress ratio $(q / p)$, deviatoric strain $\left(\varepsilon_{\mathrm{d}}\right)$ and volumetric strain $\left(\varepsilon_{\mathrm{v}}\right)$. It can be seen that the deformation and strength of soils in three-dimensional (3D) stress conditions cannot be described uniquely using these invariants. For the same tests, Fig. 9 shows the observed stress-dilatancy relation plotted using the above stress and strain increment invariants. For simplicity, the strain increment ratio can be calculated using the 


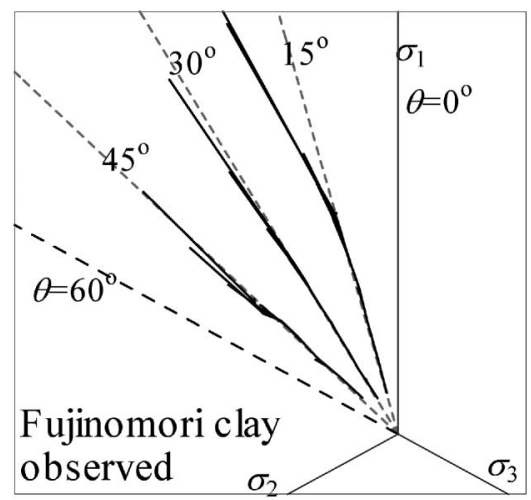

Fig. 10. Observed direction of $d \varepsilon_{\mathrm{d}}$ on the octahedral plane for drained true triaxial tests on a normally consolidated clay

total strain increments since the elastic strain increments are much smaller than the plastic strain increments under shear loadings. Because there is no unique relation between $d \varepsilon_{\mathrm{v}} / d \varepsilon_{\mathrm{d}}$ and $q / p$ in Fig. 9, the shape of yield surface on the $p$ - $q$ plane is dependent on the relative magnitude of the intermediate principal stress. Figure 10 shows the directions and the magnitudes of the observed shear strain increments on the octahedral plane for the true triaxial tests $\left(\sigma_{1}>\sigma_{2}>\sigma_{3}\right)$ with different relative values of $\sigma_{2}\left(\theta=15^{\circ}, 30^{\circ}\right.$ and $\left.45^{\circ}\right)$. Here, the length of each line is proportional to the value of the shear strain increment divided by the shear-normal stress ratio increment on the octahedral plane. In the figure, $\theta$ denotes the angle between $\sigma_{1}$-axis and the corresponding radial stress path on the octahedral plane, where $\theta=0^{\circ}$ and $60^{\circ}$ represent the stress paths under triaxial compression and triaxial extension conditions, respectively. Note that the direction of the observed shear strain increments deviates leftward from the direction of shear stress (radial direction) with the increase of stress ratio under three different principal stresses. Since the shape of plastic potential (yield surface) formulated using the stress invariants ( $p$ and $q$ ) is a circle on the octahedral plane as shown in Fig. 7, such deviation of the direction of strain increments cannot be described. Therefore, the constitutive models which are formulated using these invariants are not capable of describing properly the influence of the intermediate principal stress on the deformation and strength characteristics of soils, even if the initial stress condition and the density of soils are the same.

\section{INTRODUCING THE INFLUENCE OF INTERMEDIATE PRINCIPAL STRESS IN MODELING}

To describe the deformation and strength characteristics of soils uniquely under 3D stress conditions, Nakai and Matsuoka (1983) proposed an extended concept of the spatially mobilized plane (SMP*). Based on the generalized concept of the SMP*, Nakai and Mihara (1984) developed a method to formulate an elastoplastic model in which the influence of the intermediate principal stress can be automatically taken into consideration, by introducing the modified stress tensor $t_{\mathrm{ij}}$. In this section, the thee-dimensional modeling based on the $t_{\mathrm{ij}}$ concept is explained from the standpoint of the simple and unified method to extend one-dimensional models for geomaterials to general three-dimensional ones. Also, the physical meaning of the $t_{\mathrm{ij}}$ concept is discussed here.

\section{Definition of Modified Stress Tensor $t_{\mathrm{ij}}$ and Its Stress and Strain Increment Invariants}

In the $t_{\mathrm{ij}}$ concept, attention is focused on the so-called spatially mobilized plane (SMP; Matsuoka and Nakai, 1974) instead of the octahedral plane used in ordinary models, such as the Cam clay. The plane ABC in Fig. 11 is the spatially mobilized plane (SMP) in the three-dimensional stress space, where axes I, II and III imply the direction of three principal stresses. At each of three the sides $\mathrm{AB}, \mathrm{AC}$ and $\mathrm{BC}$ of plane $\mathrm{ABC}$, the shear-normal stress ratio is maximized between two principal stresses as shown in Fig. 12. It can be seen that the values of the coordinate axes intersected by the plane ABC (SMP) are proportional to the square root of the ratio between the corresponding principal stresses, because the following equation holds:

$$
\begin{array}{r}
\tan \left(45^{\circ}+\frac{\phi_{\text {moij }}}{2}\right)=\sqrt{\frac{1+\sin \phi_{\text {moij }}}{1-\sin \phi_{\text {moij }}}}=\sqrt{\frac{\sigma_{\mathrm{i}}}{\sigma_{\mathrm{j}}}} \\
(\mathrm{i}, \mathrm{j}=1,2,3 ; \mathrm{i}<\mathrm{j})
\end{array}
$$

Therefore, the SMP coincides with the octahedral plane only under isotropic stress conditions and varies with possible changes of stress ratio. The direction cosines $\left(a_{1}\right.$, $a_{2}$ and $a_{3}$ ) of the normal to the SMP, and the unit tensor whose principal values are determined by these direction cosines are expressed as follows (Nakai, 1989):

$$
\begin{gathered}
a_{1}=\sqrt{\frac{I_{3}}{I_{2} \sigma_{1}}}, a_{2}=\sqrt{\frac{I_{3}}{I_{2} \sigma_{2}}}, a_{3}=\sqrt{\frac{I_{3}}{I_{2} \sigma_{3}}} \\
a_{\mathrm{ij}}=\sqrt{\frac{I_{3}}{I_{2}} \cdot r_{\mathrm{ij}}^{-1}=\sqrt{\frac{I_{3}}{I_{2}}} \cdot c_{\mathrm{ik}}^{-1}\left(\sigma_{\mathrm{kj}}+I_{\mathrm{r} 2} \delta_{\mathrm{kj}}\right)} \\
\text { where } c_{\mathrm{ik}}^{-1} c_{\mathrm{kj}}=\delta_{\mathrm{ij}}, c_{\mathrm{kj}}=I_{\mathrm{r} 1} \sigma_{\mathrm{kj}}+I_{\mathrm{r} 3} \delta_{\mathrm{kj}}
\end{gathered}
$$

where $\sigma_{\mathrm{i}}(\mathrm{i}=1,2,3)$ are the three principal stresses, $I_{1}, I_{2}$, and $I_{3}$ are the first, second and third invariants of $\sigma_{\mathrm{ij}}$, and $I_{\mathrm{r} 1}, I_{\mathrm{r} 2}$ and $I_{\mathrm{r} 3}$ are the first, second and third invariants of $r_{\mathrm{ij}}$, which is the square root of the stress tensor or $r_{\mathrm{ik}} r_{\mathrm{kj}}=$ $\sigma_{\mathrm{ij}}$. These invariants are expressed using principal stresses and stress tensors as

$$
\begin{aligned}
& I_{1}=\sigma_{1}+\sigma_{2}+\sigma_{3}=\sigma_{\mathrm{ii}} \\
& \left.I_{2}=\sigma_{1} \sigma_{2}+\sigma_{2} \sigma_{3}+\sigma_{3} \sigma_{1}=\frac{1}{2}\left\{\left(\sigma_{\mathrm{ii}}\right)^{2}-\sigma_{\mathrm{ij}} \sigma_{\mathrm{ji}}\right\}\right\} \\
& I_{3}=\sigma_{1} \sigma_{2} \sigma_{3}=e_{\mathrm{ijk}} \sigma_{\mathrm{i} 1} \sigma_{\mathrm{j} 2} \sigma_{\mathrm{k} 3} \\
& I_{\mathrm{r} 1}=\sqrt{\sigma_{1}}+\sqrt{\sigma_{2}}+\sqrt{\sigma_{3}}=r_{\mathrm{ii}} \\
& I_{\mathrm{r} 2}=\sqrt{\sigma_{1} \sigma_{2}}+\sqrt{\sigma_{2} \sigma_{3}}+\sqrt{\sigma_{3} \sigma_{1}}=\frac{1}{2}\left\{\left(r_{\mathrm{ii}}\right)^{2}-r_{\mathrm{ij}} r_{\mathrm{ji}}\right\} \\
& I_{\mathrm{r} 3}=\sqrt{\sigma_{1} \sigma_{2} \sigma_{3}}=e_{\mathrm{ijk}} r_{\mathrm{i} 1} r_{\mathrm{j} 2} r_{\mathrm{k} 3}
\end{aligned}
$$

where $e_{\mathrm{ijk}}$ is the permutation tensor. The detailed expres- 


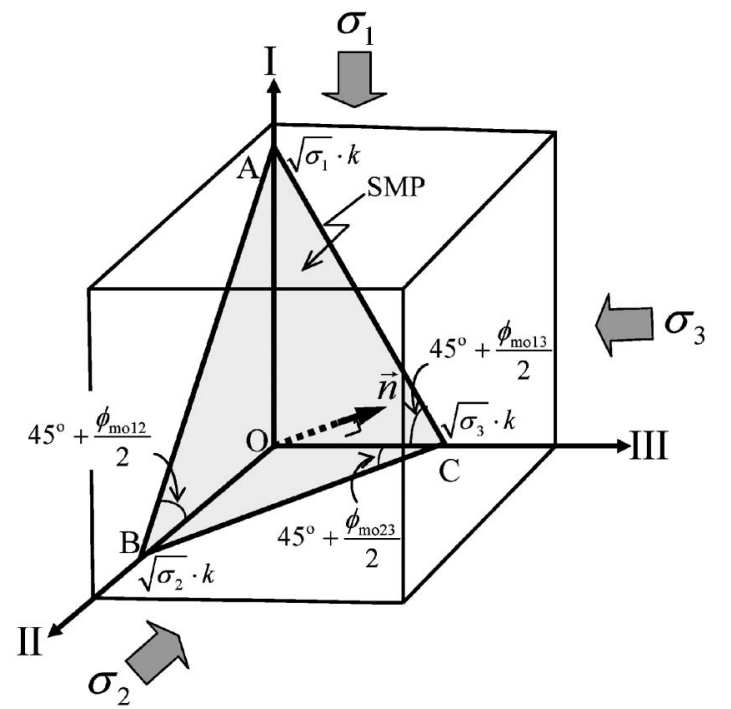

Fig. 11. Spatially mobilized plane (SMP) in three-dimensional space

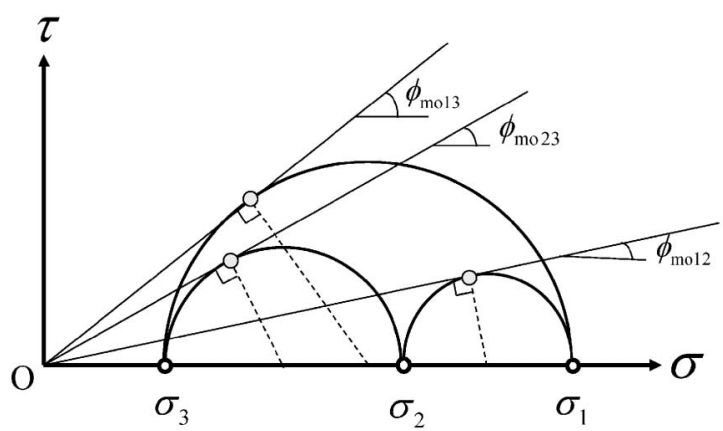

Fig. 12. Three Mohr's stress circles under three different principal stresses

sion of $a_{\mathrm{ij}}$ is also described in the paper by Nakai and Hinokio (2004). As can be seen from the above equation, $a_{\mathrm{ij}}$ is a function of stress ratio and its principal axes coincide with those of $\sigma_{\mathrm{ij}}$. The modified stress tensor $t_{\mathrm{ij}}$ is then defined by the product of $a_{\mathrm{ik}}$ and $\sigma_{\mathrm{kj}}$ as follows:

$$
t_{\mathrm{ij}}=a_{\mathrm{ik}} \sigma_{\mathrm{kj}}
$$

Its principal values are given by

$$
t_{1}=a_{1} \sigma_{1}, t_{2}=a_{2} \sigma_{2}, t_{3}=a_{3} \sigma_{3}
$$

In conventional models, the stress invariants ( $p$ and $q$ ) and strain increment invariants $\left(d \varepsilon_{\mathrm{v}}\right.$ and $\left.d \varepsilon_{\mathrm{d}}\right)$ are given by the normal and parallel components of the ordinary stress and strain increment with respect to the octahedral plane (see Figs. 1 and 2). On the other hand, the stress invariants $\left(t_{\mathrm{N}}\right.$ and $\left.t_{\mathrm{S}}\right)$ and strain increment invariants $\left(d \varepsilon_{\mathrm{N}}^{*}\right.$, $\left.d \varepsilon_{\mathrm{S}}^{*}\right)$ in the $t_{\mathrm{ij}}$ concept are defined as the normal and parallel components of the modified stress $t_{\mathrm{ij}}$ and the strain increment with respect to the SMP (see Figs. 13 and 14). Hence, these invariants are given by:

$t_{\mathrm{N}}=\overline{\mathrm{ON}}=t_{1} a_{1}+t_{2} a_{2}+t_{3} a_{3}=t_{\mathrm{ij}} a_{\mathrm{ij}}$

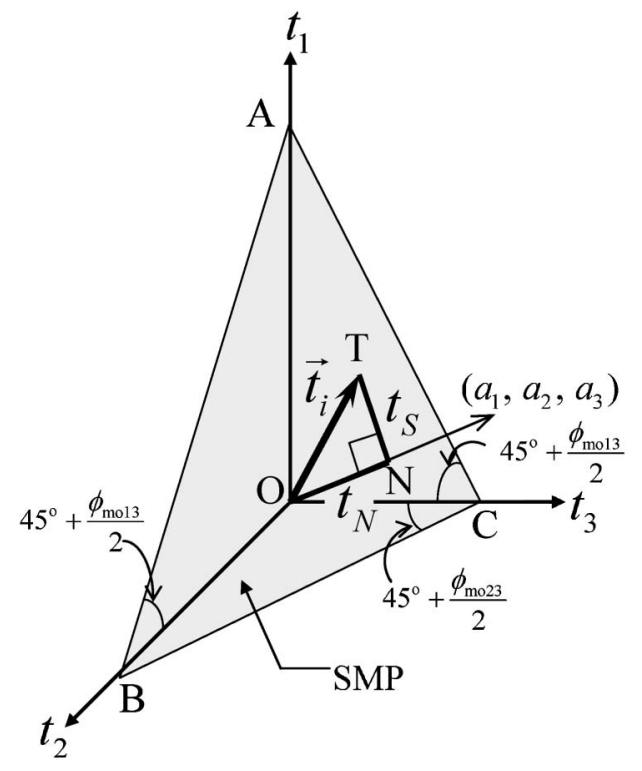

Fig. 13. Definitions of $t_{\mathrm{N}}$ and $t_{\mathrm{S}}$

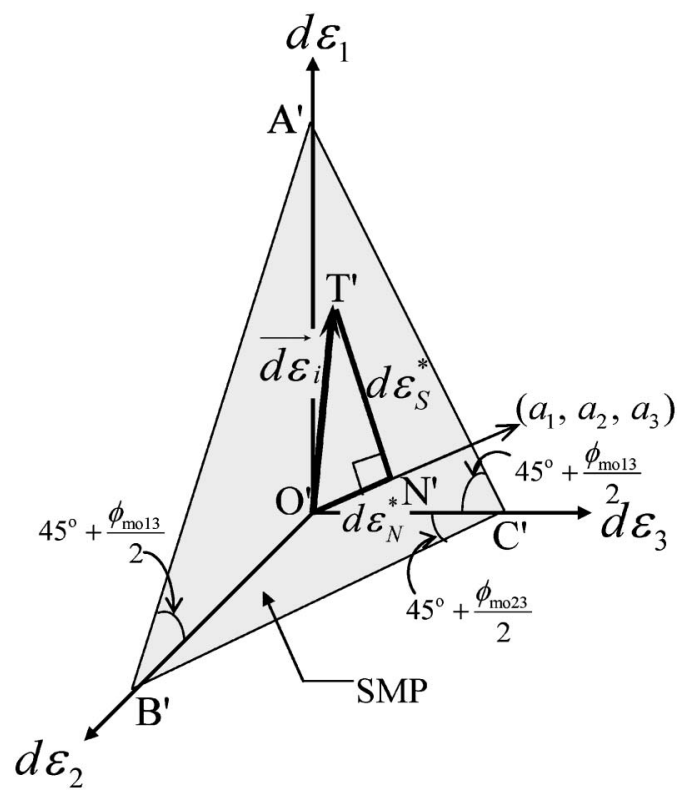

Fig. 14. Definitions of $d \varepsilon_{\mathrm{N}}^{*}$ and $d \varepsilon_{\mathrm{s}}^{*}$

$$
\begin{aligned}
& \begin{aligned}
t_{\mathrm{S}}= & \overline{\mathrm{NT}}=\sqrt{t_{1}^{2}+t_{2}^{2}+t_{3}^{2}-\left(t_{1} a_{1}+t_{2} a_{2}+t_{3} a_{3}\right)^{2}} \\
= & \sqrt{t_{\mathrm{ij}} t_{\mathrm{ij}}-\left(t_{\mathrm{ij}} a_{\mathrm{ij}}\right)^{2}}
\end{aligned} \\
& \begin{aligned}
d \varepsilon_{\mathrm{N}}^{*} & =\overline{\mathrm{O}^{\prime} \mathrm{N}^{\prime}}=d \varepsilon_{1} a_{1}+d \varepsilon_{2} a_{2}+d \varepsilon_{3} a_{3}=d \varepsilon_{\mathrm{ij}} a_{\mathrm{ij}} \\
d \varepsilon_{\mathrm{S}}^{*} & =\overline{\mathrm{N}^{\prime} \mathrm{T}^{\prime}}=\sqrt{d \varepsilon_{1}^{2}+d \varepsilon_{2}^{2}+d \varepsilon_{3}^{2}-\left(d \varepsilon_{1} a_{1}+d \varepsilon_{2} a_{2}+d \varepsilon_{3} a_{3}\right)^{2}} \\
= & \sqrt{d \varepsilon_{\mathrm{ij}} \mathrm{d} \varepsilon_{\mathrm{ij}}-\left(d \varepsilon_{\mathrm{ij}} a_{\mathrm{ij}}\right)^{2}}
\end{aligned}
\end{aligned}
$$

A comparison between the stress and strain increment tensors and their invariants used in the ordinary concept and the $t_{\mathrm{ij}}$ concept is shown in Table 1.

\section{Modeling the Influence of the Intermediate Principal Stress}

To consider the influence of the intermediate principal stress on the deformation and strength of soils in con- 
Table 1. Comparison between tensors and scalars related to stress and strain in the ordinary concept and the $t_{\mathrm{ij}}$ concept

\begin{tabular}{|c|c|c|}
\hline & ordinary concept & $t_{\mathrm{ij}}$ concept \\
\hline $\begin{array}{l}\text { tensor normal to } \\
\text { reference plane } \\
\text { stress tensor }\end{array}$ & $\begin{array}{c}\delta_{\mathrm{ij}} \\
\text { (unit tensor) } \\
\sigma_{\mathrm{ij}}\end{array}$ & $\begin{array}{c}a_{\mathrm{ij}} \\
\text { (tensor normal to SMP) } \\
t_{\mathrm{ij}}\end{array}$ \\
\hline $\begin{array}{l}\text { mean stress } \\
\text { deviatoric stress tensor } \\
\text { deviatoric stress } \\
\text { stress ratio tensor } \\
\text { stress ratio }\end{array}$ & $\begin{array}{c}p=\sigma_{\mathrm{ij}} \delta_{\mathrm{ij}} / 3 \\
S_{\mathrm{ij}}=\sigma_{\mathrm{ij}}-p \delta_{\mathrm{ij}} \\
q=\sqrt{(3 / 2) S_{\mathrm{ij}} S_{\mathrm{ij}}} \\
\eta_{\mathrm{ij}}=s_{\mathrm{ij}} / p \\
\eta=q / p\end{array}$ & $\begin{array}{c}t_{\mathrm{N}}=t_{\mathrm{ij}} a_{\mathrm{ij}} \\
t_{\mathrm{ij}}^{\prime}=t_{\mathrm{ij}}-t_{\mathrm{N}} a_{\mathrm{ij}} \\
t_{\mathrm{s}}=\sqrt{t_{\mathrm{ij}}^{\prime} t_{i \mathrm{j}}^{\prime}} \\
x_{\mathrm{ij}}=t_{\mathrm{ij}} / t_{\mathrm{N}} \\
X=t_{\mathrm{S}} / t_{\mathrm{N}}\end{array}$ \\
\hline $\begin{array}{l}\text { strain increment normal } \\
\text { to reference plane } \\
\text { deviatoric strain } \\
\text { increment tensor } \\
\text { strain increment parallel } \\
\text { to reference plane }\end{array}$ & $\begin{array}{c}d \varepsilon_{\mathrm{v}}=d \varepsilon_{\mathrm{ij}} \delta_{\mathrm{ij}} \\
d e_{\mathrm{ij}}=d \varepsilon_{\mathrm{ij}}-d \varepsilon_{\mathrm{v}} \delta_{\mathrm{ij}} / 3 \\
d \varepsilon_{\mathrm{d}}=\sqrt{(2 / 3) d e_{\mathrm{ij}} d e_{\mathrm{ij}}}\end{array}$ & $\begin{array}{c}d \varepsilon_{\mathrm{N}}{ }^{*}=d \varepsilon_{\mathrm{ij}} a_{\mathrm{ij}} \\
d \varepsilon_{\mathrm{ij}}^{\prime}=d \varepsilon_{\mathrm{ij}}-d \varepsilon_{\mathrm{N}}{ }^{*} a_{\mathrm{ij}} \\
d \varepsilon_{\mathrm{S}}^{*}=\sqrt{d \varepsilon_{\mathrm{ij}}^{\prime} d \varepsilon_{\mathrm{ij}}^{\prime}}\end{array}$ \\
\hline
\end{tabular}

stitutive modeling of soils, all that is needed is to formulate the yield function using the stress invariants $\left(t_{\mathrm{N}}\right.$ and $t_{\mathrm{S}}$ ) instead of ( $p$ and $\left.q\right)$ and to assume the flow rule in the modified stress $t_{\mathrm{ij}}$ space instead of the ordinal $\sigma_{\mathrm{ij}}$ space (Nakai and Mihara, 1984).

Figure 15 shows the yield surfaces of an elastoplastic model based on the $t_{\mathrm{ij}}$ concept, represented on the $t_{\mathrm{N}}-t_{\mathrm{S}}$ plane. The broken curve and solid curve indicate the initial and current yield surfaces when the stress condition moves from the initial state I $\left(t_{\mathrm{N}}=t_{\mathrm{N} 0}\right)$ to the current state $\mathrm{P}\left(t_{\mathrm{N}}=t_{\mathrm{N}}, X=t_{\mathrm{S}} / t_{\mathrm{N}}\right)$ with elastoplastic deformation. Here, $t_{\mathrm{N} 0}$ and $t_{\mathrm{N} 1}$ are the values of $t_{\mathrm{N}}$ on the $t_{\mathrm{N}}$-axis, which represent the sizes of the initial and current yield surfaces. The values of $p_{0}$ and $p_{1}$ in the ordinary model in Fig. 3 have a similar meaning. The yield function for the model based on the $t_{\mathrm{ij}}$ concept is given as follows by only replacing $\sigma_{0}$ and $\sigma$ in one-dimensional models not with $p_{0}$ and $p_{1}$ but with $t_{\mathrm{N} 0}$ and $t_{\mathrm{N} 1}$, respectively.

$$
\begin{aligned}
& F=H \text { or } f=F-H=0 \\
& F=(\lambda-\kappa) \ln \frac{t_{\mathrm{N} 1}}{t_{\mathrm{N} 0}}=(\lambda-\kappa)\left\{\ln \frac{t_{\mathrm{N}}}{t_{\mathrm{N} 0}}+\varsigma(X)\right\} \\
& H=(-\Delta e)^{\mathrm{p}}=\left(1+e_{0}\right) \cdot \varepsilon_{\mathrm{v}}^{\mathrm{p}} \quad\left(\text { where } X=t_{\mathrm{S}} / t_{\mathrm{N}}\right)
\end{aligned}
$$

where, $\zeta(X)$ is an increasing function of stress ratio $X(=$ $\left.t_{\mathrm{S}} / t_{\mathrm{N}}\right)$ which satisfies the condition $\zeta(0)=0$, in the same way as for $\zeta(\eta)$ in the ordinary model. Then, the plastic strain increment is calculated using an associated flow rule in $t_{\mathrm{ij}}$ space (see Fig. 15), as follows:

$$
d \varepsilon_{\mathrm{ij}}^{\mathrm{p}}=\Lambda \frac{\partial F}{\partial t_{\mathrm{ij}}}=\Lambda\left(\frac{\partial F}{\partial t_{\mathrm{N}}} \frac{\partial t_{\mathrm{N}}}{\partial t_{\mathrm{ij}}}+\frac{\partial F}{\partial X} \frac{\partial X}{\partial t_{\mathrm{ij}}}\right)
$$

The proportionality constant $\Lambda$ in the above equation is obtained from the consistency condition $(d f=0)$ just as it is in the ordinary models.

$$
\Lambda=\frac{d F}{\left(1+e_{0}\right) \frac{\partial F}{\partial t_{\mathrm{kk}}}}=\frac{d F}{h^{\mathrm{p}}} \quad\left(\text { where } d F=\frac{\partial F}{\partial \sigma_{\mathrm{ij}}} d \sigma_{\mathrm{ij}}\right)
$$

The full expressions of the derivative of $F$ with respect to

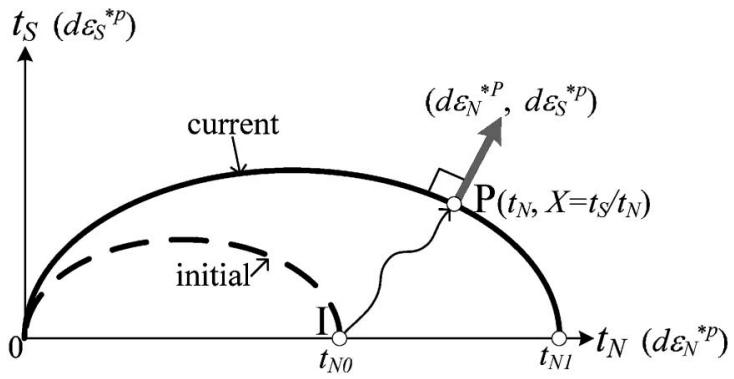

Fig. 15. Initial and current yield surfaces in the $t_{\mathrm{N}}-t_{\mathrm{S}}$ plane and direction of plastic flow for the model based on the $t_{\mathrm{ij}}$ concept

$t_{\mathrm{ij}}$ and $\sigma_{\mathrm{ij}}$ are shown in APPENDIX I.

The elastic strain increment $\mathrm{d} \varepsilon_{\mathrm{ij}}^{\mathrm{e}}$ is usually given by Eqs. (18) and (19). Considering that the elastic volumetric strain is governed not by the usual mean stress $p$ but by the mean stress $t_{\mathrm{N}}$ based on the $t_{\mathrm{ij}}$ concept in the same way as the plastic strain, then the elastic strain increment can be expressed by the following equation:

$$
d \varepsilon_{\mathrm{ij}}^{\mathrm{e}}=\frac{1+v_{\mathrm{e}}}{E_{\mathrm{e}}} d\left(\frac{\sigma_{\mathrm{ij}}}{1+X^{2}}\right)-\frac{v_{\mathrm{e}}}{E_{\mathrm{e}}} d\left(\frac{\sigma_{\mathrm{kk}}}{1+X^{2}}\right) \delta_{\mathrm{ij}}
$$

This equation derives from the fact that the following equation always holds between $p$ and $t_{\mathrm{N}}$ :

$$
t_{\mathrm{N}}=\frac{p}{1+X^{2}}
$$

The elastic modulus $E_{\mathrm{e}}$ is expressed in terms of the swelling index $\kappa$ of $e-\ln t_{\mathrm{N}}$ relation and Poisson's ratio $v_{\mathrm{e}}$ as:

$$
E_{\mathrm{e}}=\frac{3\left(1-2 v_{\mathrm{e}}\right)\left(1+e_{0}\right) t_{\mathrm{N}}}{\kappa}
$$

As an additional comment, in the elastoplastic region, the calculated stress-strain relation does not depend so much on whether or not Eq. (18) or Eq. (38) is used as the elastic component. The constitutive model for normally consolidated soils presented here essentially corresponds with the $t_{\mathrm{ij}}$-clay model (Nakai and Matsuoka, 1986).

Now, in recent models (Chowdhury and Nakai, 1998; Nakai and Hinokio, 2004), the following equation is adopted for the function of stress ratio $\zeta(X)$ in Eq. (34):

$$
\varsigma(X)=\frac{1}{\beta}\left(\frac{X}{M^{*}}\right)^{\beta}
$$

where $\beta(\geqq 1)$ is a parameter which controls the shape of the yield function. When $\beta=1$, the shape of yield function is the same as that of the original Cam-clay model. From Eqs. (34), (36) and (41), the following stressdilatancy relation holds:

$$
\frac{d \varepsilon_{\mathrm{N}}^{*}{ }^{*}}{d \varepsilon_{\mathrm{S}}^{\mathrm{p}}}=\frac{\frac{\partial F}{\partial t_{\mathrm{N}}}+\frac{\partial F}{\partial X} \frac{\partial X}{\partial t_{\mathrm{N}}}}{\frac{\partial F}{\partial X} \frac{\partial X}{\partial t_{\mathrm{S}}}}=\frac{1-\zeta^{\prime}(X) \cdot X}{\zeta^{\prime}(X)}=\frac{\left(M^{*}\right)^{\beta}-X^{\beta}}{X^{\beta-1}}
$$

Figure 16 illustrates this equation in terms of the relation between $X=t_{\mathrm{S}} / t_{\mathrm{N}}$ and $Y=d \varepsilon_{\mathrm{N}}^{* \mathrm{p}} / d \varepsilon_{\mathrm{S}}^{* \mathrm{p}}$. Here, $M^{*}$ implies the intercept with the vertical axis and is calculated using 


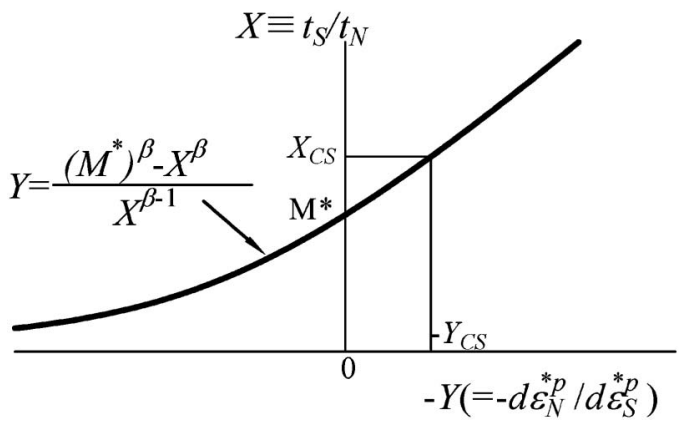

Fig. 16. Stress-dilatancy relation of recent $t_{\mathrm{ij}}$ model

$X_{\mathrm{CS}}$ and $Y_{\mathrm{CS}}$, which are the stress ratio $X$ and the plastic strain increment ratio $Y$ at critical state $\left(\mathrm{d} \varepsilon_{\mathrm{v}}^{\mathrm{p}}=0\right)$.

$$
M^{*}=\left(X_{\mathrm{CS}}^{\beta}+X_{\mathrm{CS}}^{\beta-1} Y_{\mathrm{CS}}\right)^{1 / \beta}
$$

The values of $X_{\mathrm{CS}}$ and $Y_{\mathrm{CS}}$ are expressed as follows using the principal stress ratio at critical state in triaxial compression $R_{\mathrm{CS}}=\left(\sigma_{1} / \sigma_{3}\right)_{\mathrm{CS}(\text { (comp) }}$ (Nakai and Mihara, 1984):

$$
\begin{gathered}
X_{\mathrm{CS}}=\frac{\sqrt{2}}{3}\left(\sqrt{R_{\mathrm{CS}}}-\frac{1}{\sqrt{R_{\mathrm{CS}}}}\right) \\
Y_{\mathrm{CS}}=\frac{1-\sqrt{R_{\mathrm{CS}}}}{\sqrt{2}\left(\sqrt{R_{\mathrm{CS}}}+0.5\right)}
\end{gathered}
$$

The dots in Fig. 17 shows the observed stress-dilatancy relation of the same tests shown in Fig. 9, arranged in terms of the relation between the stress ratio $t_{\mathrm{S}} / t_{\mathrm{N}}$ and the strain increment ratio $d \varepsilon_{\mathrm{N}}^{*} / d \varepsilon_{\mathrm{S}}^{*}$. It can be seen that although the relation between $q / p$ and $\mathrm{d} \varepsilon_{v} / \mathrm{d} \varepsilon_{\mathrm{d}}$ in Fig. 9 is strongly influenced by the intermediate principal stress, the stress-dilatancy relation based on $t_{\mathrm{ij}}$ concept is independent of the intermediate principal stress. Since the magnitude of the elastic strain increments is much smaller than that of the plastic strain increments under shear loading, the stress-dilatancy relation in Eq. (42) also holds uniquely. Figure 18 shows a view of the yield surface of $t_{\mathrm{ij}}$ model in the principal spaces of $\sigma_{\mathrm{ij}}$ and $t_{\mathrm{ij}}$ (Pedroso et al., 2005). The shape of the yield surface on the octahedral plane in the $\sigma_{\mathrm{ij}}$ space is a rounded triangle and corresponds to that of the SMP criterion (Matsuoka and Nakai, 1974) (see diagram (c)). The shape of the yield surface in the $t_{\mathrm{ij}}$ space is also an oval, though a little more rounded, but it is not a circle (see diagram (d)). Therefore, the $t_{\mathrm{ij}}$ concept can describe not only the observed uniqueness of stress-dilatancy relation (Fig. 17) but also the observed deviation of plastic flow vector from the direction of shear stress on the octahedral plane (Fig. 10). Employing the $t_{\mathrm{ij}}$ concept-i.e., the stress term $F$ in the yield function is formulated in such a form as Eq. (34), and assuming the flow rule in the $t_{\mathrm{ij}}$ space as Eq. (36), the influence of intermediate principal stress in constitutive modeling can be automatically taken into consideration.

\section{The Meaning of the $t_{\mathrm{ij}}$ Concept}

The meaning of the $t_{\mathrm{ij}}$ concept is discussed here, focusing mostly on the microscopic point of view. Several

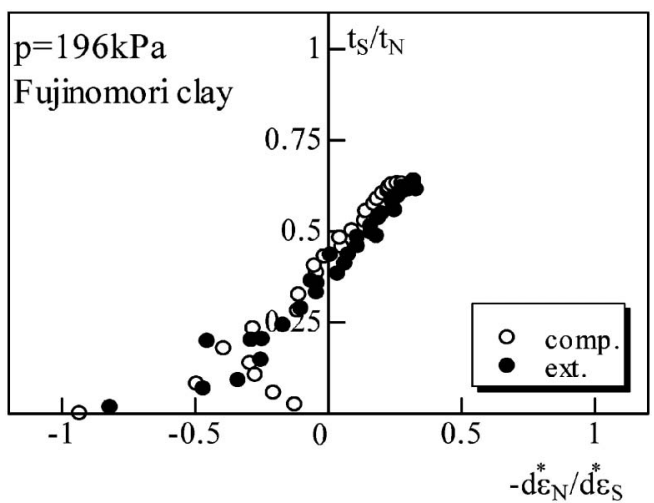

Fig. 17. $t_{\mathrm{S}} / t_{\mathrm{N}}$ vs. $d \varepsilon_{\mathrm{N}}^{*} / d \varepsilon_{\mathrm{S}}^{*}$ relation of drained triaxial compression and extension tests on a normally consolidated clay

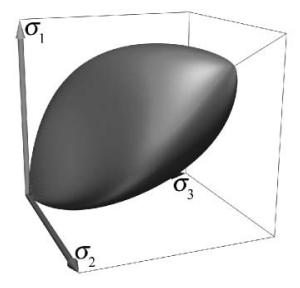

(a) Space $\sigma_{1} \times \sigma_{2} \times \sigma_{3}$

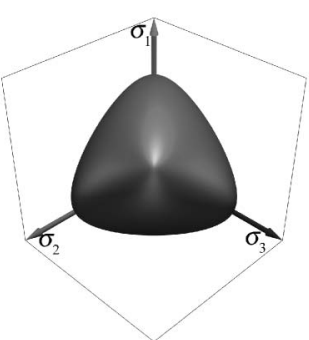

(c) View from hydrostatic axis $\sigma_{1}=\sigma_{2}=\sigma_{3}$

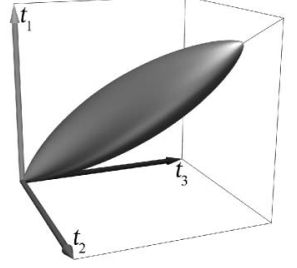

(b) Space $t_{1} \times t_{2} \times t_{3}$

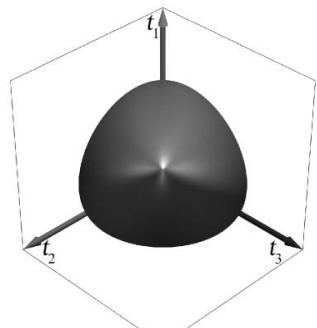

(d) View from hydrostatic axis $t_{1}=t_{2}=t_{3}$
Fig. 18. Shape of yield surface in the principal spaces of $\sigma_{\mathrm{ij}}$ and $t_{\mathrm{ij}}$ (Pedroso et al., 2005)

researchers have shown that induced anisotropy of soils developed with the change of stresses is characterized by the frequency distribution of the inter-particle contact angles. It has then been shown from microscopic observation (e.g., Oda, 1972) and DEM simulation (e.g., Maeda et al, 2006) that, as the stress ratio increases, the average directions normal to the inter-particle contacts gradually concentrate in the same direction as the major principal stress $\left(\sigma_{1}\right)$. Based on the results of biaxial tests on a stack of photoelastic bars, Satake (1984) pointed out that the principal values $\left(\varphi_{1}, \varphi_{2}\right)$ of the so-called fabric tensor $\varphi_{\mathrm{ij}}$, which represents the relative distribution of the number of vectors normal to the inter-particle contacts, is approximately proportional to the square root of the corresponding principal stresses. Maeda et al. (2006) also carried out two-dimensional (2D) DEM simulations of biaxial tests and obtained the same results, expressed as: 

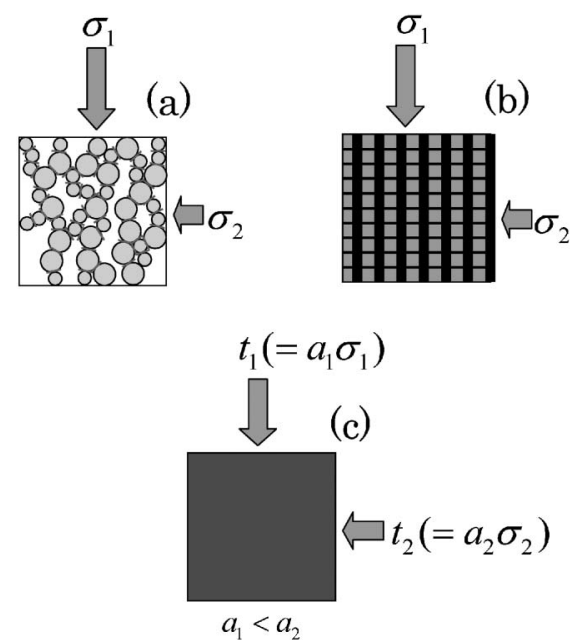

Fig. 19. Anisotropy and its expression

$$
\frac{\varphi_{1}}{\varphi_{2}} \cong\left(\frac{\sigma_{1}}{\sigma_{2}}\right)^{0.5}
$$

Employing a fabric tensor, Satake (1982) also proposes the following modified stress tensor $\sigma_{\mathrm{ij}}^{*}$ to analyze the behavior of granular materials:

$$
\sigma_{\mathrm{ij}}^{*}=\frac{1}{3} \varphi_{\mathrm{ik}}^{-1} \sigma_{\mathrm{kj}}
$$

Figure 19(a) shows a schematic distribution of inter-particle contacts in the $2 \mathrm{D}$ condition. Considering the equivalent continuum, such material exhibits anisotropy since the stiffness in the $\sigma_{1}$ direction is larger than that in the $\sigma_{2}$ direction as the stress ratio increases, as shown in diagram (b). When adopting an elastoplastic theory, it is reasonable to treat the soil as an isotropic material by introducing the modified stress $t_{\mathrm{ij}}$, which takes induced anisotropy into consideration. This is because the normality rule, where the direction of plastic flow is normal to the yield surface (plastic potential) holds in the isotropic space, like the transformed space used to analyze seepage problems in anisotropic ground and others. As shown in Eq. (23), the principal values of $a_{\mathrm{ij}}$ are inversely proportional to the square root of the respective principal stresses, therefore:

$$
a_{1}: a_{2}=\frac{1}{\sqrt{\sigma_{1}}}: \frac{1}{\sqrt{\sigma_{2}}}
$$

By comparison, it can be noted that $a_{\mathrm{ij}}$ corresponds to the inverse of the fabric tensor in Eq. (46), and $t_{\mathrm{ij}}$ defined by Eq. (27) corresponds to the modified stress introduced by Satake (1982) in Eq. (47). As shown in diagram (c) of Fig. 19 , the stress ratio $t_{1} / t_{2}$ in the modified stress space is smaller than the stress ratio $\sigma_{1} / \sigma_{2}$ in the ordinary stress space since $a_{1}$ is smaller than $a_{2}$, as Eq. (48) shows. Then, it is reasonable to assume that the flow rule (normality condition) holds not in the $\sigma_{\mathrm{ij}}$ space but in the $t_{\mathrm{ij}}$ space, because the condition of the anisotropic material under the anisotropic stress ratio in diagram (b) can be considered the same as that of the isotropic material under the lower stress ratio, as shown in diagram (c) in Fig. 19. The above explanation of modified stress holds for the case where anisotropy is developed under monotonic loading without the rotation of principal stress axes. A method to determine the modified stress under general cyclic loading with the rotation of the principal stress axes is described in another paper (Kikumoto et al., 2009).

Next, the reason for defining the stress and strain increment invariants used in the $t_{\mathrm{ij}}$ concept as the normal and parallel components of the stress and strain increments with respect to the SMP instead of the octahedral plane is explained. Since the irrecoverable behavior of materials, such as metal, is governed mostly by deviatoric stress (or shear stress) alone, it is reasonable to take the plane where shear stress is maximized (in 2D condition) and the averaged plane where shear stress between two principal stresses is maximized-i.e., octahedral plane (in 3D condition)-into consideration. On the other hand, the irrecoverable behavior of geomaterials, such as soil, is governed by the frictional law between particles-i.e., shear-normal stress ratio. Therefore, attention should be paid to the plane where shear-normal stress ratio is maximized, i.e., the mobilized plane (in 2D condition), and the plane combined by the three planes where the shearnormal stress ratio between two respective principal stresses is maximized, i.e., the SMP (in $3 \mathrm{D}$ condition). In this sense, it is natural to formulate constitutive models using the normal and parallel components of the stress and strain increments referred to the SMP. As a consequence, the influence of the intermediate principal stress on induced anisotropy and frictional resistance is introduced by adopting the $t_{\mathrm{ij}}$ concept.

\section{THREE-DIMENSIONAL MODELING OF OVER CONSOLIDATED SOIL BASED ON ADVANCED ELASTOPLASTICITY (STAGE I)}

The above-mentioned elastoplastic model based on the $t_{\mathrm{ij}}$ concept for normally consolidated soils is extended here to a model for over consolidated soils, introducing the subloading surface concept proposed by Hashiguchi (1980) and revising it. It is assumed that the stress condition changes from point I to point $\mathrm{P}$ in Fig. 15. Since $t_{\mathrm{N} 1}$ moves from $t_{\mathrm{N} 0}$ to $t_{\mathrm{N} 1}$, the plastic change of void ratio $(-\Delta e)_{\mathrm{NC}}^{\mathrm{p}}$ for a normally consolidated soil is given by:

$$
\begin{aligned}
(-\Delta e)_{\mathrm{NC}}^{\mathrm{p}} & =\left(e_{\mathrm{N} 0}-e_{\mathrm{N}}\right)-(-\Delta e)^{\mathrm{e}} \\
& =(-\Delta e)_{\mathrm{NC}}-(-\Delta e)^{\mathrm{e}}=(\lambda-\kappa) \ln \frac{t_{\mathrm{N} 1}}{t_{\mathrm{N} 0}}
\end{aligned}
$$

As shown in Fig. 20, the initial and current void ratios for over consolidated soils are expressed as $e_{0}$ and $e$ and the state variable $\rho$ which represents the influence of density is defined as $\rho=e_{\mathrm{N}}-e$ and its initial value is $\left(\rho_{0}=e_{\mathrm{N} 0}\right.$ $-e_{0}$ ) in the same way as in the one-dimensional advanced model (stage I) described by Nakai et al. (2011). Then, the corresponding plastic change in void ratio $(-\Delta e)^{\mathrm{p}}$ for over consolidated soils is expressed as: 


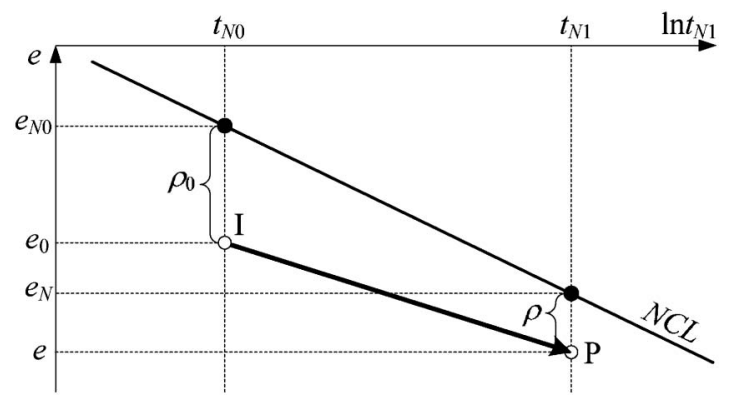

Fig. 20. Change of void ratio in an over consolidated soil

$$
\begin{aligned}
(-\Delta e)^{\mathrm{p}} & =(-\Delta e)_{\mathrm{NC}}^{\mathrm{p}}-\left(\rho_{0}-\rho\right) \\
& =(\lambda-\kappa) \ln \frac{t_{\mathrm{N} 1}}{t_{\mathrm{N} 0}}-\left(\rho_{0}-\rho\right)
\end{aligned}
$$

From this equation, the yield function for over consolidated soils is expressed using $F$ and $H$ defined by Eqs. (34) and (35) in the same form as that in one-dimensional model.

$$
\left.F+\rho=H+\rho_{0} \quad \text { or } \quad f=F-\left\{H+\rho_{0}-\rho\right)\right\}=0
$$

The consistency condition $(d f=0)$ and the flow rule in Eq. (36) give

$$
\begin{aligned}
d f & =d F-\{d H-d \rho\} \\
& =d F-\left\{d(-e)^{\mathrm{p}}-d \rho\right\} \\
& =d F-\left\{\left(1+e_{0}\right) \Lambda \frac{\partial F}{\partial t_{\mathrm{ii}}}-d \rho\right\}=0
\end{aligned}
$$

It can be assumed that the positive value of $\rho$ decreases and finally becomes zero with the development of plastic strains in the same way as in the one-dimensional model (Nakai et al., 2011). The proportionality constant $\Lambda(>0)$ which represents the magnitude of the plastic deformation has the dimension of stress, because $F$ is a dimensionless function. Then, $\left(\partial F / \partial t_{\mathrm{ii}}\right)$ has the dimension of the inverse of stress. To satisfy these conditions, the following evolution rule of $\rho$ is given using a monotonic increasing function $G(\rho)$ which satisfies $G(0)=0$ :

$$
d \rho=-\left(1+e_{0}\right) \frac{G(\rho)}{t_{\mathrm{N}}} \Lambda
$$

As mentioned in the one-dimensional model (Nakai, et al., 2011), any increasing function $G(\rho)$ which satisfies $G(0)=0$ can be employed. Since variable $\rho$ may become negative, in the same way as one-dimensional model, the function $G(\rho)$ in the present model is given by the following equation so as to be increasing function even if $\rho<0$ :

$$
G(\rho)=\operatorname{sign}(\rho) \cdot a \rho^{2}
$$

Substituting Eq. (53) into Eq. (52), the proportionality constant $\Lambda$ is expressed as

$$
\Lambda=\frac{d F}{\left(1+e_{0}\right)\left\{\frac{\partial F}{\partial t_{\mathrm{ii}}}+\frac{G(\rho)}{t_{\mathrm{N}}}\right\}}=\frac{d F}{h^{\mathrm{p}}}
$$

In the modeling based on the subloading surface concept (Hashiguchi, 1980), it is assumed that the current stress
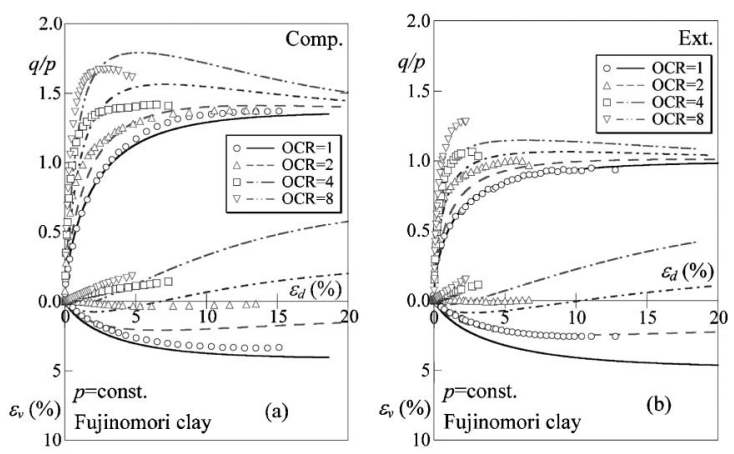

Fig. 21. Triaxial compression and extension tests on Fujinomori clay
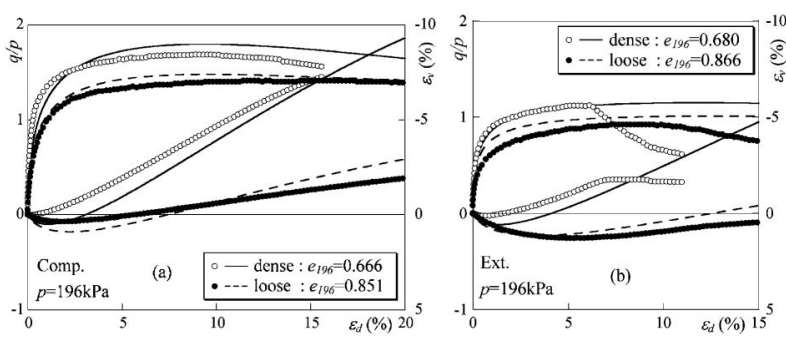

Fig. 22. Triaxial compression and extension tests on Toyoura sand

point always passes over the yield surface (subloading surface) whether plastic deformation occurs or not. Also, the loading condition is given by:

$$
\begin{cases}d \varepsilon_{\mathrm{ij}}^{\mathrm{p}} \neq 0 & \text { if } \Lambda=\frac{d F}{h^{\mathrm{p}}}>0 \\ d \varepsilon_{\mathrm{ij}}^{\mathrm{p}}=0 & \text { otherwise }\end{cases}
$$

Then, the plastic strain increment is calculated as:

$$
d \varepsilon_{\mathrm{ij}}^{\mathrm{p}}=\langle\Lambda\rangle \frac{\partial F}{\partial t_{\mathrm{ij}}}=\left\langle\frac{d F}{h^{\mathrm{p}}}\right\rangle \frac{\partial F}{\partial t_{\mathrm{ij}}}
$$

where, the symbol \langle\rangle denotes the Macaulay bracket, i.e., $\langle A\rangle=A$ if $A>0$; otherwise $\langle A\rangle=0$. The present model in which the evolution rule of $\rho$ is given by Eqs. (53) and (54) coincides with the previously proposed subloading $t_{\mathrm{ij}}$ model (Nakai and Hinokio, 2004).

Figure 21 shows the observed (symbols) and calculated (curves) results of triaxial compression and extension tests on remolded Fujinomori clay with different over consolidation ratios $(\mathrm{OCR}=1,2,4$ and 8$)$. Here, tests with $\mathrm{OCR}=8$ were carried out under $p=98 \mathrm{kPa}$, and the other tests were performed under $p=196 \mathrm{kPa}$. The model is capable of uniquely describing not only the influence of over consolidation ratio (density) on the deformation, dilatancy and strength of clay but also the influence of intermediate principal stress on them. Figure 22 shows the observed (symbols) and calculated (curves) results of constant mean principal tests on dense and loose Toyoura sand. The model can describe the stress-strain-strength behavior of sands under triaxial compression and extension conditions from dense to loose states with a unified set of material parameters, in the same way as for clays. The values of the material parameters for Fujinomori 
Table 2. Material parameters for Fujinomori clay and Toyoura sand in model at stage $I$

\begin{tabular}{c|c|l|l}
\hline & $\begin{array}{c}\text { Fujinomori } \\
\text { clay }\end{array}$ & $\begin{array}{c}\text { Toyoura } \\
\text { sand }\end{array}$ & \\
\hline$\lambda$ & 0.104 & 0.070 & \\
$\kappa$ & 0.010 & 0.0045 & Same parameters as \\
$N\left(e_{\mathrm{N}}\right.$ at $\left.p=98 \mathrm{kPa}\right)$ & 0.83 & 1.10 & Cam clay model \\
$R_{\mathrm{CS}}=\left(\sigma_{1} / \sigma_{3}\right)_{\mathrm{CS}(\text { comp. })}$ & 3.5 & 3.2 & \\
$v_{\mathrm{e}}$ & 0.2 & 0.2 & \\
\hline$\beta$ & 1.5 & 2.0 & $\begin{array}{l}\text { Shape of yield surface } \\
\text { (same as original Cam } \\
\text { clay if } \beta=1)\end{array}$ \\
\hline$a /(\lambda-\kappa)$ & 500 & 30 & Influence of density \\
\hline
\end{tabular}

clay and Toyoura sand are shown in Table 2. In the simulations in the present paper, the elastic strains are evaluated with Eq. (18) instead of Eq. (38), due to the following reasons: there is not much difference in the results between both equations as mentioned before, the elastic strains are much smaller than the plastic strains, and Eq. (18) is usually more popular than Eq. (38). The validity of the present model (subloading $t_{\mathrm{ij}}$ model) has been confirmed by the test results under various stress conditions including under three different principal stresses (Nakai and Hinokio, 2004).

\section{THREE-DIMENSIONAL MODELING OF STRUCTURED SOIL BASED ON ADVANCED ELASTOPLASTICITY (STAGE II)}

It is assumed that the stress-strain behavior of structured soil can be described by considering not only the effect of density described above but also the effect of bonding, in the same way as in the one-dimensional model. When the stress condition moves from point I to point $\mathrm{P}$ in Fig. 15, the change of void ratio for a structured soil is also expressed as shown in Fig. 20 and Eq. (50). Then, the yield function is given by Eq. (51), which means that Eq. (52) holds for structured soils as well. As described in one-dimensional modeling (Nakai et al., 2011), the evolution rule of $\rho$ with the development of plastic deformation for structured soils can be determined not only by the state variable $\rho$ related to density but also by the state variable $\omega$ representing the bonding effect with an imaginary increase of density, and the value of the state variable $\omega$ has an additional effect on the degradation of $\rho$. The evolution rule of $\rho$ is then given as follows using not only $G(\rho)$ but also an increasing function $Q(\omega)$, which satisfies $Q(0)=0$ :

$$
d \rho=-\left(1+e_{0}\right)\left\{\frac{G(\rho)}{t_{\mathrm{N}}}+\frac{Q(\omega)}{t_{\mathrm{N}}}\right\} \Lambda
$$

The evolution rule of $\omega$ is given as follows using the same function $Q(\omega)$, although it is possible to use another function:

$$
d \omega=-\left(1+e_{0}\right) \frac{Q(\omega)}{t_{\mathrm{N}}} \Lambda
$$
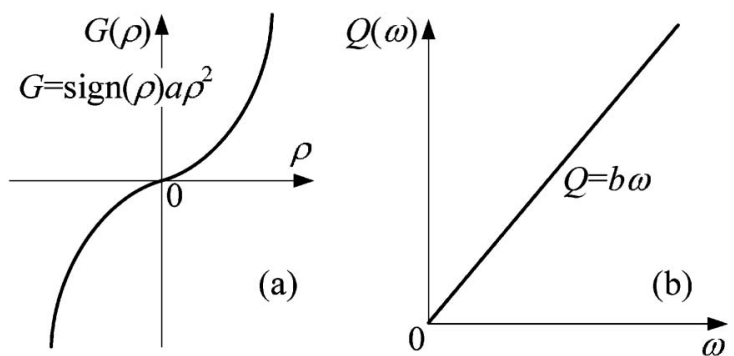

Fig. 23. Functions $G(\rho)$ and $Q(\omega)$ for evolution rule of $\rho$

Table 3. Added material parameter for Fujinomori clay in model at stage II considering bonding effect

\begin{tabular}{l|l|l}
\hline$b /(\lambda-\kappa)$ & 40 & Influence of bonding \\
\hline
\end{tabular}

In the present model, the following linear increasing function $Q(\omega)$ is adopted:

$$
Q(\omega)=b \omega
$$

The plastic strain increment is then obtained by the flow rule based on the $t_{\mathrm{ij}}$ concept in Eq. (57). Substituting Eq. (58) into Eq. (52), the proportionality constant $\Lambda$ is expressed as

$$
\Lambda=\frac{d F}{\left(1+e_{0}\right)\left\{\frac{\partial F}{\partial t_{\mathrm{ii}}}+\frac{G(\rho)}{t_{\mathrm{N}}}+\frac{Q(\omega)}{t_{\mathrm{N}}}\right\}}=\frac{d F}{h^{\mathrm{p}}}
$$

As described in the one-dimensional model (Nakai, et al., 2011), since there is the possibility that the value of $\rho$ becomes negative for the soils with bonding, the domain of the increasing function $G(\rho)$ is extended to the negative side. Therefore, a positive value of $\rho$ has the effect of increasing the plastic modulus; and, on the other hand, a negative value of $\rho$ has the effect of decreasing the plastic modulus. Figure 23 illustrates the functions $G(\rho)$ and $Q(\omega)$ for the evolution rule of $\rho$ and $\omega$. The elastic components and the loading condition are the same as those for the model at stage I.

Simulations for a structured clay are carried out to confirm the performance of the present model. The values of the material parameters used in the simulations are the same as those for Fujinomori clay in Table 2. One single parameter $(b)$ for the bonding effect, which assumed the value $b /(\lambda-\kappa)=40$ as shown in Table 3 , were added. The present model coincides with the model described in a previous paper (Nakai, 2007), although the derivation processes of the present model is more logical. Figure 24 shows the results, arranged in terms of the relations between void ratio and vertical stress in log scale, of simulations using the three-dimensional model for oedometer tests on structured clays which have the same initial void ratio but have different initial bonding effects. Here, the solid line with $\omega_{0}=0.0$ represents the result for the non-structured soil. It is seen that three-dimensional model can also describe the typical one-dimensional consolidation behavior of structured soils in the same way as 


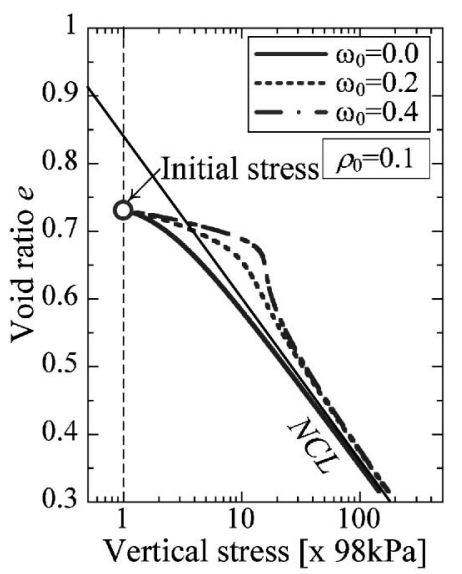

Fig. 24. Simulation of oedometer tests on a clay with same initial void ratio but different initial bonding
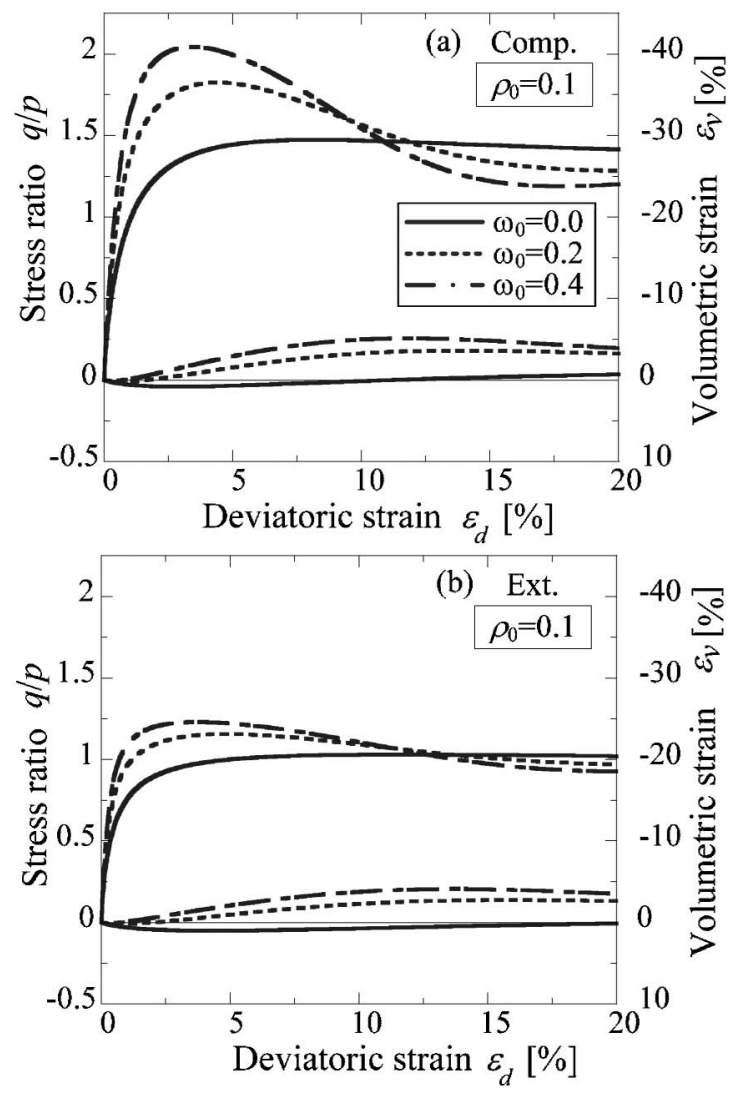

Fig. 25. Simulation of drained triaxial compression and extension tests $(p=98 \mathrm{kPa})$ on a clay with same initial void ratio but different initial bonding

those simulated by the one-dimensional model in the related paper. Figure 25 shows the results of simulations of constant mean principal stress tests $(p=98 \mathrm{kPa})$ on the same clay under triaxial compression and extension conditions. The initial stiffness, the peak strength and dilatancy become larger with the increase of the bonding effect, even if the initial void ratio is the same. Figure 26 shows the results of simulations of undrained triaxial compression and extension tests $\left(p_{0}^{\prime}=98 \mathrm{kPa}\right)$ on the
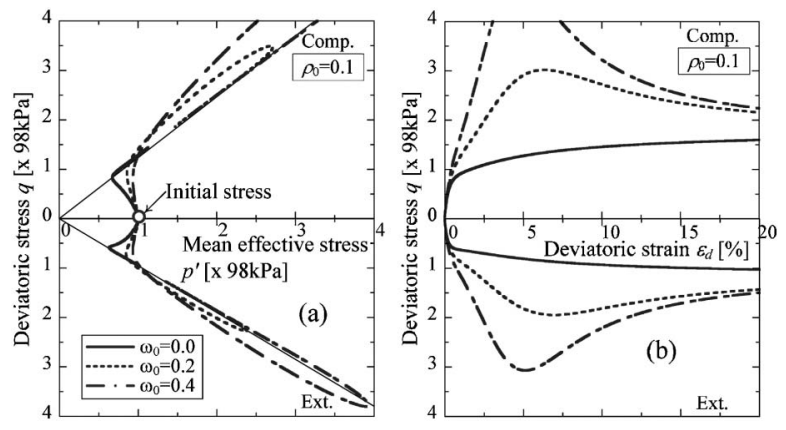

Fig. 26. Simulation of undrained triaxial compression and extension tests on a clay with same initial void ratio but different initial bonding

same clay. Diagram (a) shows the results of effective stress paths, and diagram (b) shows the results of stressstrain curves. In these figures, the upper part depicts the results under triaxial compression condition, and lower part shows the results under triaxial extension condition. The straight lines from the origin in diagram (a) represent the critical state lines (CSL) in the $p$ - $q$ plane. Under undrained shear loadings, clays with bonding are stiffer and have higher strength than clays without bonding. It is also seen that over consolidated clays without bonding $\left(\omega_{0}=0.0\right)$ show strain hardening with the decrease and the subsequent increase of mean stress, whereas clays with bonding $\left(\omega_{0}=0.2,0.4\right)$ show not only strain hardening with the decrease and the subsequent increase of mean stress but also strain softening with the decrease of mean stress and deviatoric stress under undrained conditions. These are the typical undrained behaviors of structured soils.

Figure 27 shows the results of simulations of isotropic compression and the subsequent undrained shear tests on a structured clay. Diagram (a) shows the consolidation curve of a structured clay (initial state: $e_{0}=0.73\left(\rho_{0}=0.1\right)$, $\omega_{0}=0.4$ at $p_{0}=98 \mathrm{kPa}$ ) from stress condition (A). Diagrams (b) and (c) show the results of effective stress paths and stress-strain curves in undrained triaxial compression tests on the clays which are sheared from stress conditions (A), (B) and (C) in diagram (a). Figure 28 shows the observed results of undrained shear tests on undisturbed Osaka Pleistocene clay (Ma12) published by Asaoka et al. (2000b). Here, OC(e) represents the result under initial confining pressure $p_{0}^{\prime}=98 \mathrm{kPa}$ (over consolidation state), and $\mathrm{NC}(\mathrm{e})$ represents the result under $p_{0}^{\prime}=490 \mathrm{kPa}$ (almost the same stress as the overburden pressure in situ). The authors (Asaoka et al., 2000b; Asaoka, 2005) also carried out the simulations of structured soils using the SYS Cam clay model (Asaoka et al., 2000a), in which the subloading surface concept (to increase the plastic modulus) and the superloading surface concept (to decrease the plastic modulus) are introduced in the Cam clay model. Similarly, as can be seen from Eq. (61) in the present model, $G(\rho)$ and $Q(\omega)$ have the effects of increasing the plastic modulus in the cases where $\rho$ and $\omega$ are positive. Only in the case when $\rho$ becomes negative (the 

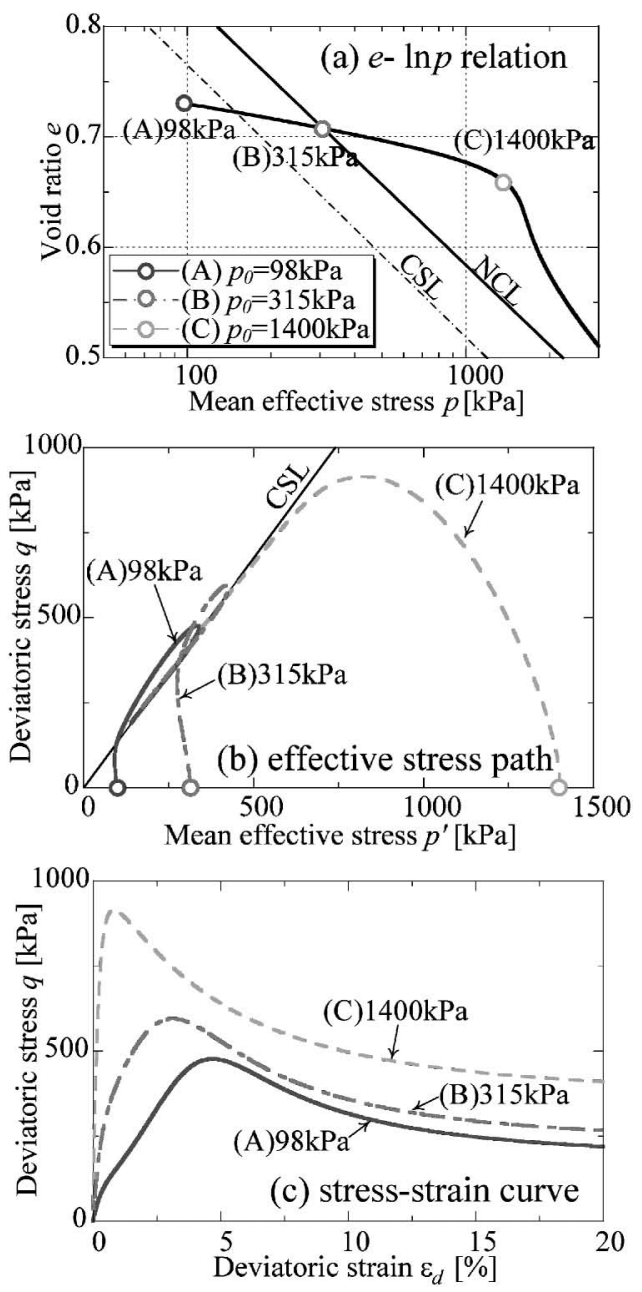

Fig. 27. Calculated results of isotropic compression and subsequent undrained shear tests on a structured clay

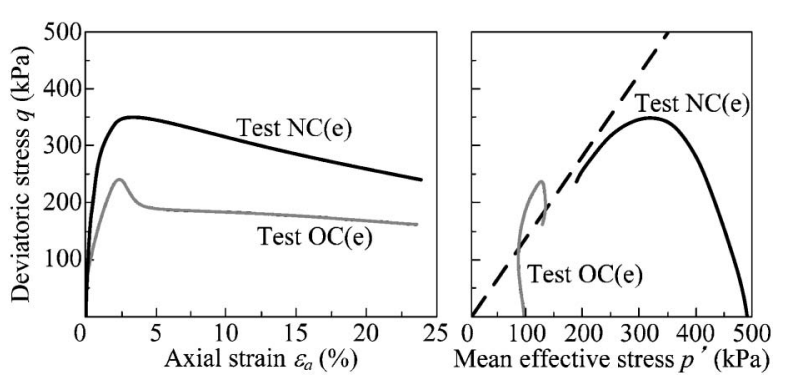

Fig. 28. Observed results of undrained shear tests on undisturbed Osaka Pleistocene clay (Ma12) (replotted from data in Asaoka et al., 2000b)

current void ratio is larger than that on NCL), $G(\rho)$ has an effect of decreasing the plastic modulus. The model proposed here simulates well the typical undrained shear behavior of structured soils under different confining pressures, such as the differences of stress paths and stress-strain curves depending on the magnitude of the confining pressure. It also reproduces the rewinding of stress path after increasing of mean stress and deviatoric stress and other effects.

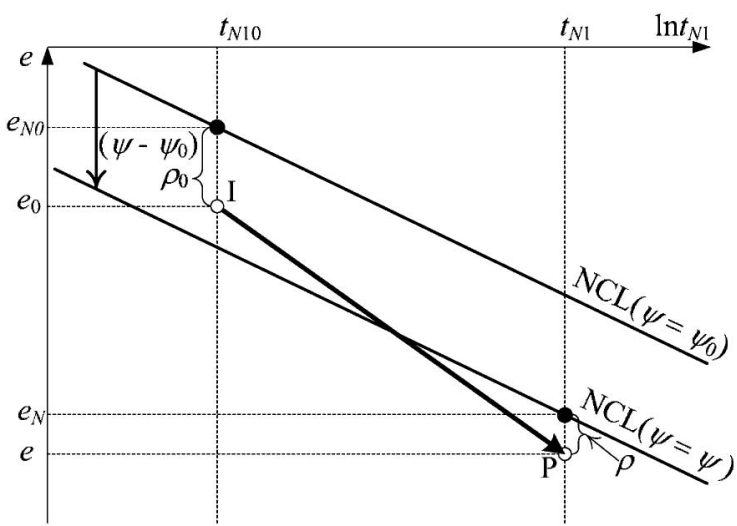

Fig. 29. Change of void ratio in a soil with changes in $\rho$ and $\psi$

\section{THREE-DIMENSIONAL MODELING OF SOME OTHER FEATURES BASED ON ADVANCED ELASTOPLASTICITY (STAGE III)}

\section{General Modeling}

Experimental tests have shown that the normal consolidation line (NCL) and the critical state line (CSL) shift on the $e-\ln p\left(\right.$ or $\left.e-\ln t_{\mathrm{N}}\right)$ plane depending on strain rate, temperature, suction (saturation) and other effects, as described in the related paper (Nakai et al., 2011). To take these features into consideration in a three-dimensional model, the $e-\ln t_{\mathrm{N} 1}$ relation in Fig. 29 is obtained for the change of the stress condition from point I to point $\mathrm{P}$ in Fig. 15. Here, $\psi$, which is a state variable to determines the position of NCL, is related to the strain rate, temperature, suction (saturation) or other effect, as it is in the one-dimensional model, and $\psi_{0}$ is the initial value of $\psi$. The plastic change of void ratio is then expressed as:

$$
\begin{aligned}
(-\Delta e)^{\mathrm{p}} & =\left\{\left(e_{\mathrm{N} 0}-e_{\mathrm{N}}\right)-(-\Delta e)^{\mathrm{e}}\right\}-\left(\rho_{0}-\rho\right) \\
& =\left\{(\lambda-\kappa) \ln \frac{t_{\mathrm{N} 1}}{t_{\mathrm{N} 0}}+\left(\psi-\psi_{0}\right)\right\}-\left(\rho_{0}-\rho\right)
\end{aligned}
$$

Then, the yield function can be written as follows using $F$ and $H$ :

$$
\begin{aligned}
& F+\rho+\psi=H+\rho_{0}+\psi_{0} \\
& \text { or } \\
& f=F-\left\{H+\left(\rho_{0}-\rho\right)+\left(\psi_{0}-\psi\right)\right\}=0
\end{aligned}
$$

From the consistency condition $(d f=0)$ and the flow rule in Eq. (36), the following expression can be obtained:

$$
\begin{aligned}
d f & =d F-\{d H-d \rho-d \psi\} \\
& =d F-\left\{d(-e)^{\mathrm{p}}-d \rho-d \psi\right\} \\
& =d F-\left\{\left(1+e_{0}\right) \Lambda \frac{\partial F}{\partial t_{\mathrm{ii}}}-d \rho-d \psi\right\}=0
\end{aligned}
$$

Since $d \rho$ is related with the proportionality constant $\Lambda$ by Eq. (58), $\Lambda$ is expressed as

$$
\Lambda=\frac{d F+d \psi}{\left(1+e_{0}\right)\left\{\frac{\partial F}{\partial t_{\mathrm{kk}}}+\frac{G(\rho)}{t_{\mathrm{N}}}+\frac{Q(\omega)}{t_{\mathrm{N}}}\right\}}=\frac{d F+d \psi}{h^{\mathrm{p}}}
$$

As described in the modeling at stage I and stage II, the yield surface always passes over the current stress and the 
plastic deformation occurs when $\Lambda>0$. Therefore, the plastic strain increment in the model of stage III is given by

$$
d \varepsilon_{\mathrm{ij}}^{\mathrm{p}}=\langle\Lambda\rangle \frac{\partial F}{\partial t_{\mathrm{ij}}}=\left\langle\frac{d F+d \psi}{h^{\mathrm{p}}}\right\rangle \frac{\partial F}{\partial t_{\mathrm{ij}}}
$$

The formulation of the present three-dimensional model was developed in such a way that it coincides with the subloading $t_{\mathrm{ij}}$ model developed by Nakai and Hinokio (2004) and Nakai (2007). Although the validation of the model under isotropic compression (or one-dimensional compression) is the similar to that of the one-dimensional model described in the related paper (Nakai et al., 2011), there are some small quantitative differences between the results of simulations using both models. Another formulation of three-dimensional model in which the results of simulations coincide perfectly with those of the onedimensional model under isotropic compression on over consolidated soils and structured soils is presented in APPENDIX II.

\section{Application of Model to Time-dependent Behavior}

In the one-dimensional time-dependent model, the state variable $\psi$ is related to the rate of the plastic void ratio change $(-\dot{e})^{\mathrm{p}}$ as described in the related paper (Nakai et al., 2011). However, in the multi-dimensional stress condition, $(-\dot{e})^{\mathrm{p}}$ (or the plastic volumetric strain rate $\dot{\varepsilon}_{\mathrm{v}}^{\mathrm{p}}$ ) is not necessarily positive during plastic deformation because of soil dilatancy, and then the rate of plastic void ratio change (or plastic volumetric strain rate) is not suitable for measuring time-dependent behavior. Since the norm of the plastic strain rate $\left\|\dot{\varepsilon}_{\mathrm{ij}}^{\mathrm{p}}\right\|$ is always positive during plastic deformation even in multi-dimensional conditions and gives the magnitude of the plastic strain rate, it seems logical to relate $\psi$ with some quantity using the norm of the plastic strain rate. Leroueil and Marques (1996) shows, from experimental results of oedometer tests and undrained and drained shear tests on a clay, that the time-dependent behavior of clays under consolidation and shear can be arranged uniquely using the norm of the strain rate as the strain rate measure. Besides, it is known that the void ratio change for normally consolidated soils subjected to pure creep conditions under isotropic compression satisfies a linear $e$-ln $t$ relation with the slope of $\lambda_{\alpha}$ (the coefficient of secondary consolidation) in the same way as that in one-dimensional model. Now, under isotropic compression, the norm of plastic strain rate $\left\|\varepsilon_{\mathrm{ij}}^{\mathrm{p}}\right\|$ is expressed as follows using the rate of plastic void ratio change $(-\dot{e})^{\mathrm{p}}$

$$
\begin{aligned}
\left\|\dot{\varepsilon}_{\mathrm{ij}}^{\mathrm{p}}\right\| & =\sqrt{\dot{\varepsilon}_{\mathrm{ij}}^{\mathrm{p}} \dot{\varepsilon}_{\mathrm{ij}}^{\mathrm{p}}}=\sqrt{\dot{\varepsilon}_{1}^{\mathrm{p} 2}+\dot{\varepsilon}_{2}^{\mathrm{p} 2}+\dot{\varepsilon}_{3}^{\mathrm{p} 2}}=\sqrt{3} \dot{\varepsilon}_{1}^{\mathrm{p}} \\
& =\frac{\dot{\varepsilon}_{\mathrm{v}}^{\mathrm{p}}}{\sqrt{3}}=\frac{(-\dot{e})^{\mathrm{p}}}{\sqrt{3}\left(1+e_{0}\right)}
\end{aligned}
$$

Although the state variable $\psi$ and its initial value $\psi_{0}$ in one-dimensional model are related with $t$ and $t_{0}$ or $(-\dot{e})^{\mathrm{p}}$ and $(-\dot{e}) \mathrm{p}$, as described in the related paper (Nakai et al., 2011), $\psi$ and $\psi_{0}$ in three-dimensional model are given by the same formula as that in the one-dimensional model using $(-\dot{e})_{(\text {equ })}^{\mathrm{p}}$ instead of $(-\dot{e})^{\mathrm{p}}$.

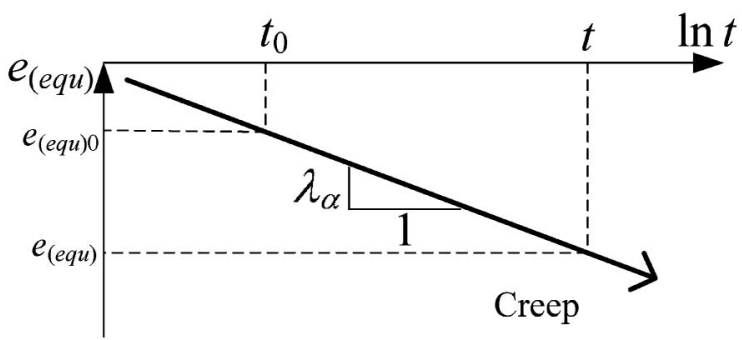

Fig. 30. Creep characteristics of normally consolidated soils in general stress conditions

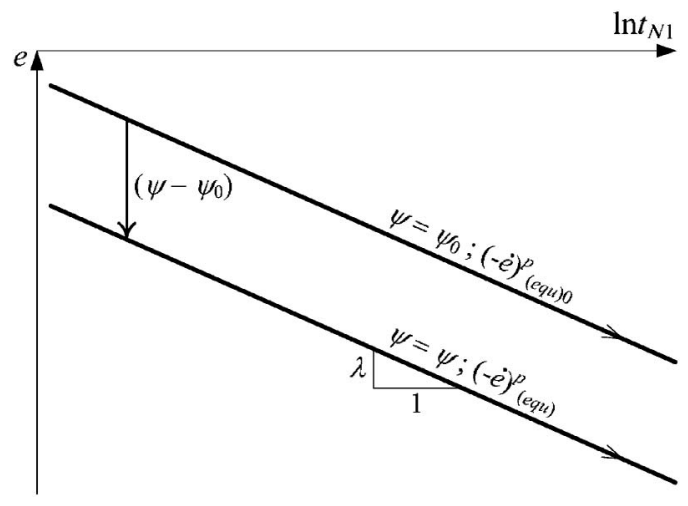

Fig. 31. Position of NCL depending on rate of equivalent void ratio change

$$
\left(\begin{array} { l } 
{ \psi = \lambda _ { \alpha } \operatorname { l n } t } \\
{ \psi _ { 0 } = \lambda _ { \alpha } \operatorname { l n } t _ { 0 } }
\end{array} \quad \text { or } \quad \left(\begin{array}{l}
\psi=-\lambda_{\alpha} \ln (-\dot{e})_{(\mathrm{equ})}^{\mathrm{p}} \\
\psi_{0}=-\lambda_{\alpha} \ln (-\dot{e})_{(\mathrm{equ}) 0}^{\mathrm{p}}
\end{array}\right.\right.
$$

Here, it is assumed that $(-\dot{e})_{(\text {equ }}^{\mathrm{p}}$ is an equivalent rate of plastic void ratio change, which is defined by Eq. (67) not only under isotropic compression but also under any other stress condition.

$$
(-\dot{e})_{(\text {equ })}^{\mathrm{p}}=\sqrt{3}\left(1+e_{0}\right)\left\|\dot{\varepsilon}_{\mathrm{ij}}^{\mathrm{p}}\right\|
$$

This formulation means that for a normally consolidated soil under pure creep condition there is a linear relation between $e_{\text {(equ) }}$ and $\ln t$ with a slope of $\lambda_{\alpha}$, regardless of the stress condition, as shown in Fig. 30. Therefore, the increment of $\psi$ is expressed as:

$$
d \psi=\frac{\partial \psi}{\partial t} d t=\lambda_{\alpha} \frac{1}{t} d t=(-\dot{e})_{(\mathrm{equ})}^{\mathrm{p}} d t
$$

The position of the NCL shifts depending on the equivalent rate of plastic void ratio change defined by Eq. (69), as shown in Fig. 31.

Substituting Eq. (70) into Eq. (65), the proportionality constant $\Lambda$ for the model considering time-dependent behavior can be obtained:

$$
\begin{aligned}
\Lambda & =\frac{d F+(-\dot{e})_{(\text {equ })}^{\mathrm{p}} d t}{\left(1+e_{0}\right)\left\{\frac{\partial F}{\partial t_{\mathrm{kk}}}+\frac{G(\rho)}{t_{\mathrm{N}}}+\frac{Q(\omega)}{t_{\mathrm{N}}}\right\}} \\
& =\frac{d F+(-\dot{e})_{(\text {equ })}^{\mathrm{p}} d t}{h^{\mathrm{p}}} \cong \frac{d F+(-\dot{e})_{(\text {equ })}^{\mathrm{p}^{*}} d t}{h^{\mathrm{p}}}
\end{aligned}
$$


Here, $(-\dot{e})_{(\text {(equ) }}^{\mathrm{p}^{*}}$ denotes the equivalent rate of plastic void ratio change at the calculation step immediately before the current one, in the same way as in the one-dimensional model. Also, the position of the NCL $(\psi)$ for the next calculation step can be determined by Eq. (68) using the updated value of $(-\dot{e})_{(\text {equ) }}^{\mathrm{p}}$.

Table 4. Added material parameter for Fujinomori clay in timedependent model

\begin{tabular}{c|c|l}
\hline$\lambda_{\alpha}$ & 0.003 & Coefficient of secondary consolidation \\
\hline$(-\dot{e})_{\text {(equ)ref }}^{\mathrm{p}}$ & $1 \times 10^{-7} / \mathrm{min}$ & $\begin{array}{l}\text { Equivalent rate of plastic void ratio } \\
\text { change at reference state }\end{array}$ \\
\hline
\end{tabular}
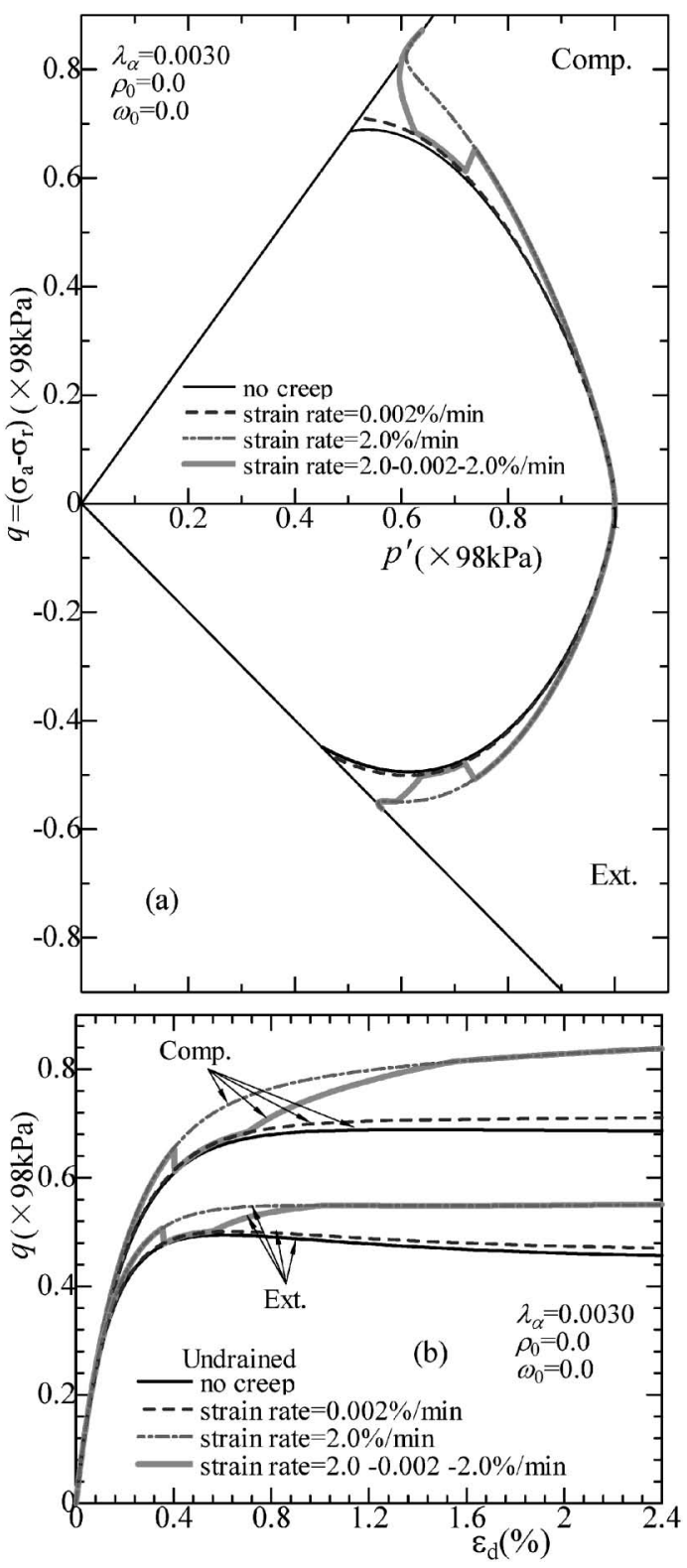

Fig. 32. Simulation of undrained triaxial compression and extension tests on a normally consolidated clay with different strain rates
Simulation of Time-dependent Behavior of Soil in Threedimensional Conditions

The validity of the proposed time-dependent model is checked by performing some simulations of constant strain rate tests, creep tests and others on normally consolidated clay, over consolidated clay and structured clay. The material parameters used in the simulation are the same as those of Fujinomori clay in Table 2. The parameter $b$ for the bonding effect is the same as that in Table 3 . The values of the added material parameters for describing time-dependent behavior are shown in Table $4-i . e .$, the coefficient of secondary consolidation $\lambda_{\alpha}$ and the equivalent rate of plastic void ratio change at the reference state $(-\dot{e})_{\text {(equ)ref }}^{\mathrm{p}}$. In the following simulations, the initial equivalent rate of plastic void ratio change is assumed to be the same as that at the reference state
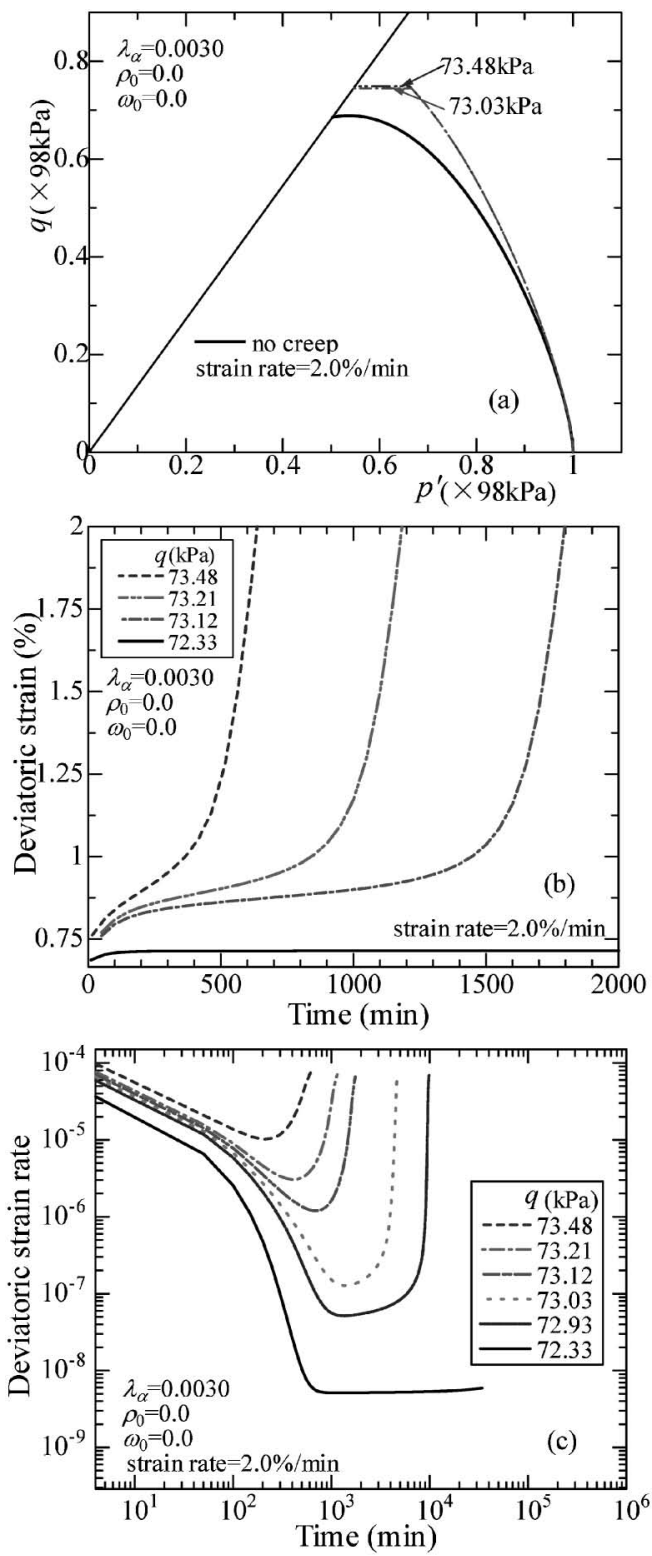

Fig. 33. Simulation of undrained creep tests after constant strain rate $\left(\dot{\varepsilon}_{\mathrm{a}}=\mathbf{2 . 0} \% / \mathrm{min}\right)$ triaxial compression tests on a normally consolidated clay 

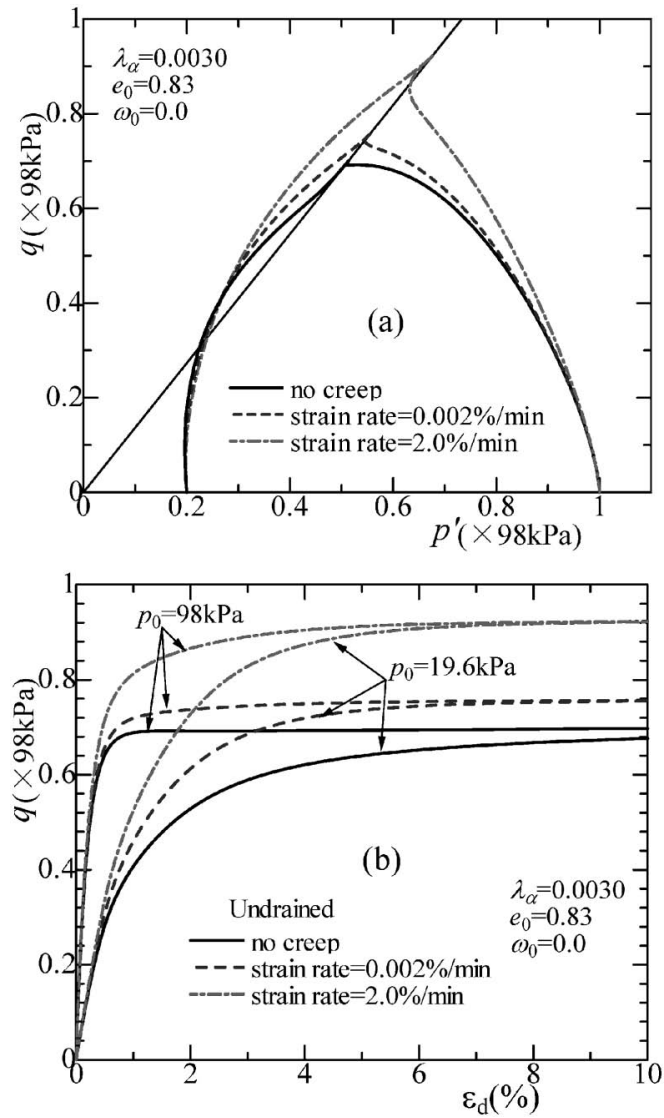

Fig. 34. Simulation of undrained triaxial compression tests on normally consolidated and over consolidated clays with different strain rates

$(-\dot{e})_{\text {(equ) } 0}^{\mathrm{p}}=(-\dot{e})_{\text {(equ)ref }}^{\mathrm{p}}$.

Figure 32 shows the calculated results ((a) effective stress paths, (b) stress-strain curves) of undrained triaxial compression and extension tests with different axial strain rates $\dot{\varepsilon}_{\mathrm{a}}$ on a normally consolidated clay $\left(\rho_{0}=0.0, \omega_{0}=\right.$ $0.0)$. Here, the curves named 'no creep' represent the results without time-effect, and the thick curves indicate the results of the tests in which the strain rate changes from $2.0 \% / \mathrm{min}$ to $0.002 \% / \mathrm{min}$ and then $2.0 \% / \mathrm{min}$ during shear. The model can describe well-known rate effects on the strength and the development of pore water pressure-higher undrained shear strength and less pore pressure development with increasing strain rates. It is also seen that the calculated stress-strain state shifts between the corresponding stress-strain curves and effective stress paths when the strain rate changes during shear, a phenomenon known as 'isotache'.

Figure 33 shows the calculated results of undrained creep on a normally consolidated clay under triaxial compression condition. The clay is sheared up to a certain deviatoric stress condition with the strain rate of $\dot{\varepsilon}_{\mathrm{a}}=$ $2.0 \% / \mathrm{min}$, and then the deviatoric stress is kept constant. Diagram (a) shows the stress paths during shear and creep condition, diagram (b) shows the creep curves during creep, and diagram (c) presents the relation between strain rate and elapsed time during creep. It can be seen that the model represents the typical undrained creep
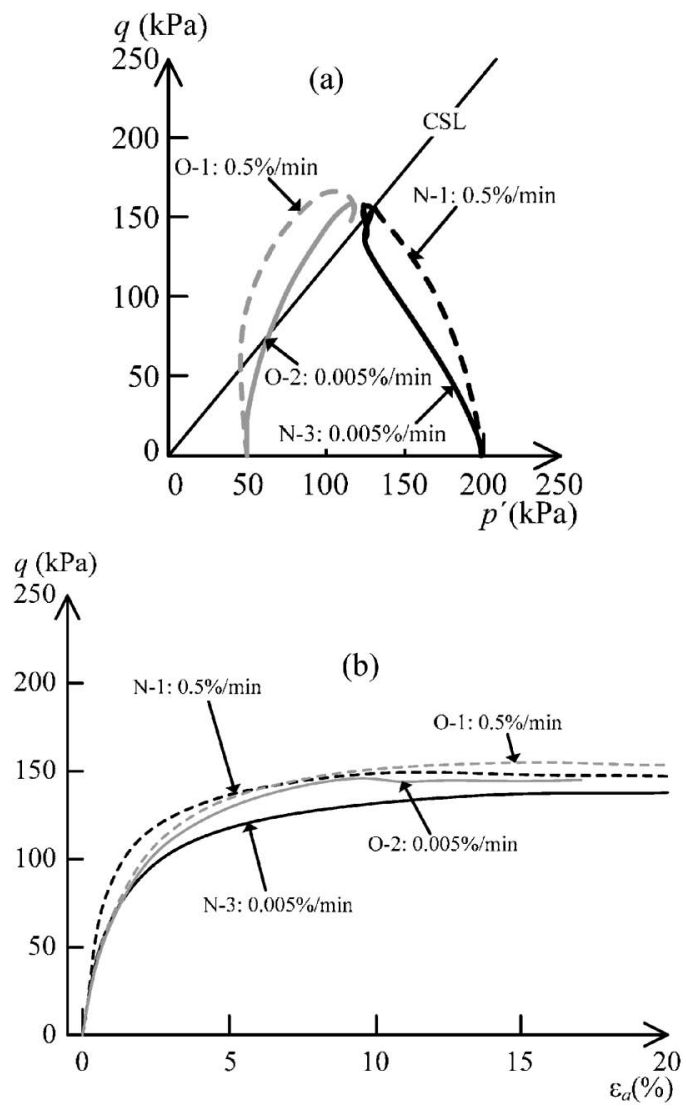

Fig. 35. Observed results of undrained triaxial compression tests on normally consolidated and over consolidated Fukakusa clays with different strain rates (replotted from data in Oka et al., 2003)

behavior including transient creep, stationary creep and accelerating creep (e.g., Sekiguchi, 1984).

Figure 34 shows the calculated results ((a) the effective stress paths, (b) the stress-strain curves) of undrained compression tests under different strain rates on the normally and over consolidated clays with the same initial void ratio $\left(e_{0}=0.83\right)$ and the same initial equivalent rate of void ratio change $\left((-\dot{e})_{\text {equ }) 0}^{\mathrm{p}}=1 \times 10^{-7} / \mathrm{min}\right)$. In these figures, the results of the normally consolidated clay $\left(p_{0}\right.$ $=98 \mathrm{kPa}$ ) are the same as those under triaxial compression tests in Fig. 32. It can be seen that although the mean stress $p$ in the fast test is smaller than that of the slow test at the same deviatoric stress $q$ for the normally consolidated clay with negative dilatancy, the tendency for the over consolidated clay with positive dilatancy is the opposite. Figure 35 shows the observed results of undrained triaxial compression tests on remolded Fukakusa clay in normally consolidated states (N-1, N-3) and over consolidated states $(\mathrm{O}-1, \mathrm{O}-2)$ with different axial strain rates (Oka et al., 2003). The initial void ratios of these samples vary from 1.16 to 1.18 . The differences of the strain rate effect on the soil behavior between the normally consolidated clays and the over consolidated clays derived from the present model simulations correspond qualitatively with the observed test results in Fig. 35. Asaoka et al. (1997) also performed undrained triaxial compression tests on a remolded over consolidated clay with different 

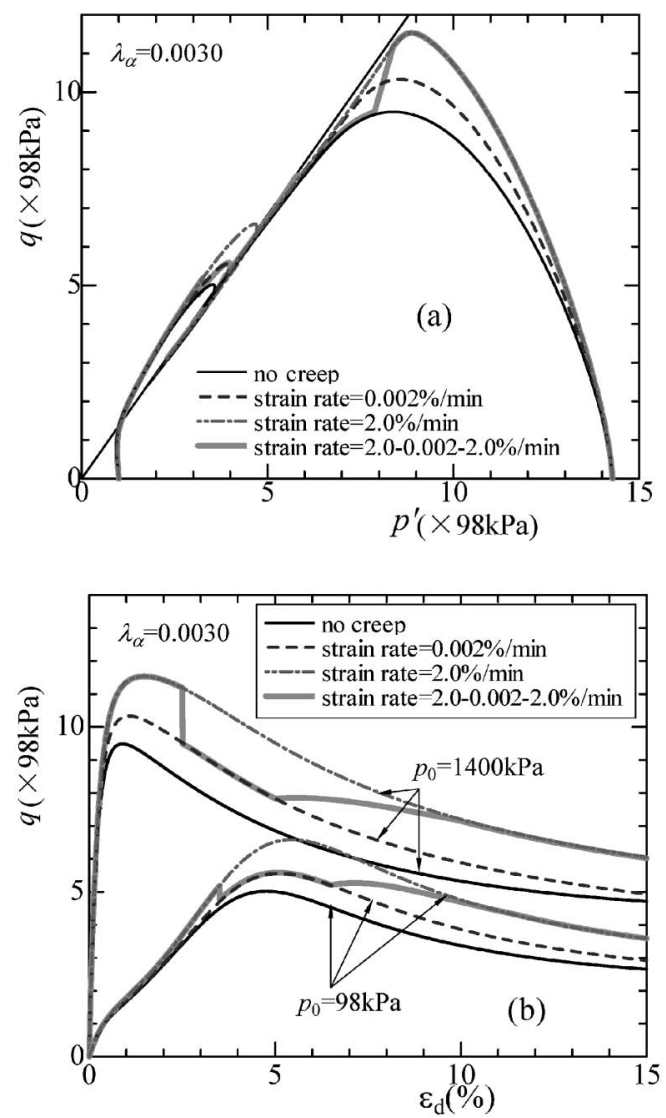

Fig. 36. Simulation of undrained triaxial compression tests on a structured clay with different initial conditions and different strain rates

strain rates and reproduced the same strain rate effects on over consolidated clays, by performing a soil-water coupled analysis using their elastoplastic model.

Simulations of undrained triaxial compression tests on a structured clay with different strain rates are shown in Fig. 36. Here, the structured clay is sheared under undrained condition with different strain rates from the conditions (A) and (C) in Fig. 27(a). Diagram (a) shows the effective stress paths and diagram (b) shows the stressstrain curves. As mentioned when commenting Fig. 32, the curves represented by 'no creep' are the results without time-effect, and the thick curves indicate the results of the tests in which the strain rate changes from $2.0 \% / \mathrm{min}$ to $0.002 \% / \mathrm{min}$ and then $2.0 \% / \mathrm{min}$ during shear. The phenomenon of 'isotache' has been observed experimentally in structured soils as well as in non-structured soils (e.g., Graham et al., 1983). It can be seen that the present model describes such time-dependent behavior of structured soils as well.

\section{CONCLUSIONS}

After interpreting the simple and unified method-named $t_{\mathrm{ij}}$ concept-to extend one-dimensional models (or conventional models, such as the Cam clay model which uses the stress invariants $p$ and $q$ ) to threedimensional models capable of taking the influence of the intermediate principal stress on soil deformation and strength into consideration, the one-dimensional models presented in the related paper (Nakai et al., 2011) were extended to three-dimensional ones using the $t_{\mathrm{ij}}$ concept. The main results of this paper are summarized as follows:

(1) The framework of ordinary three-dimensional elastoplastic models for soils such as the Cam clay model using the stress invariants $p$ and $q$ was shown. It was clarified on the basis of experimental results that such models can not consider the influence of the intermediate principal stress on the deformation and strength of soils properly.

(2) The concept of $t_{\mathrm{ij}}$ by which the influence of the intermediate principal stress can be automatically taken into account in three-dimensional modeling was described in details, and its physical meaning was discussed. A general method to extend any one-dimensional model to three-dimensional conditions using the $t_{\mathrm{ij}}$ concept was presented.

(3) The one-dimensional model for over consolidated soils based on the modeling at stage I described in the related paper was extended to three-dimensional conditions. This model, which is formulated using the state variable $\rho$ to consider the density in the same way as in the one-dimensional model, coincides with the subloading $t_{\mathrm{ij}}$ model proposed before. It was shown that the present model can describe the stressstrain behavior of soils including positive and negative dilatancy under different void ratio in general stress conditions using the same material parameters used in the one-dimensional model.

(4) The one-dimensional model for structured soils described in the related paper was extended to threedimensional conditions. To describe the behavior of structured soils, not only the state variable $\rho$ but also another state variable $\omega$ was introduced (modeling at stage II). This model can describe well-known drained and undrained shear behavior of structured soils subjected to three-dimensional stresses as well as the consolidation behavior, adding only one extra material parameter.

(5) For describing other features of soils in three-dimensional stress conditions, the one-dimensional model was also extended to a three-dimensional one, by introducing the other state variable $\psi$ (modeling at stage III). The three-dimensional time-dependent model for non-structured and structured soils with various densities was formulated using this state variable, in the same way as in the one-dimensional model. This model can describe various time dependent behaviors of normally consolidated soils, over consolidated soils and structured soils, such as strain rate effect on shear behavior, creep behavior and others. The added material parameter for considering time-dependent behavior is the coefficient of secondary consolidation alone.

A simple and unified method to describe various soil features such as the influences of density, bonding effect and time-dependent behavior were presented using three state variable $(\rho, \omega$ and $\psi)$. Besides these features, it may 
be possible to describe temperature-dependent behavior, the behavior of unsaturated soil, and the influence of particle crushing as well using these three state variables and determining their evolution rules. Furthermore, the $t_{\mathrm{ij}}$ concept, which is used for extending one-dimensional models to general three-dimensional ones, may be utilized to take into consideration the stress induced anisotropy as well.

\section{ACKNOWLEDGMENTS}

This study was supported financially in part by the Grant-in-Aid for Scientific Research (B-22360184, Teruo Nakai) from the Ministry of Education, Science and Culture of Japan.

\section{NOTATION}

$a$ : material parameter to describe the influence of density and/or confining pressure

$a_{1}, a_{2}$ and $a_{3}$ : principal values of $a_{\mathrm{ij}}$-i.e., direction cosines of normal to the spatially mobilized plane (SMP)

$a_{\mathrm{ij}}$ : symmetric tensor whose principal value are given by $a_{1}, a_{2}$ and $a_{3}$

$b$ : material parameter to describe the influence of bonding

$d \varepsilon_{\mathrm{N}}^{*}$ : strain increment invariant in $t_{\mathrm{ij}}$ concepti.e., normal component of $d \varepsilon_{\mathrm{ij}}$ with respect to the SMP

$d \varepsilon_{\mathrm{S}}^{*}$ : strain increment invariant in $t_{\mathrm{ij}}$ concepti.e., parallel component of $d \varepsilon_{\mathrm{ij}}$ with respect to the SMP

$e:$ void ratio

$e_{\mathrm{N}}$ : void ratio on the normally consolidation line (NCL)

$f=0$ : yield function

$h^{\mathrm{p}}$ : plastic modulus

$k$ : coefficient of permeability

$p$ : stress invariant used in ordinary modelsi.e., mean principal stress

$p_{1}$ : value of $p$ on $p$-axis for the current yield surface

$q$ : stress invariant used in ordinary modelsi.e., deviatoric stress

$t:$ time

$t_{1}, t_{2}$ and $t_{3}$ : principal value of $t_{\mathrm{ij}}$

$t_{\mathrm{ij}}$ : modified stress tensor based on the $t_{\mathrm{ij}}$ concept $\left(=a_{\mathrm{ik}} \sigma_{\mathrm{kj}}\right)$

$t_{\mathrm{N}}$ : stress invariant in $t_{\mathrm{ij}}$ concept-i.e., normal component of $t_{\mathrm{ij}}$ with respect to the SMP

$t_{\mathrm{N} 1}$ : value of $t_{\mathrm{N}}$ on $t_{\mathrm{N}}$-axis for the current yield surface

$t_{\mathrm{S}}$ : stress invariant in the $t_{\mathrm{ij}}$ concept-i.e., parallel component of $t_{\mathrm{ij}}$ with respect to the SMP

$E_{\mathrm{e}}$ : tangential Young's modulus of the elastic component
$F$ : stress term in the yield function $\left(=(\lambda-\kappa) \ln \left(p_{1} / p_{0}\right)\right.$ or $\left.(\lambda-\kappa) \ln \left(t_{\mathrm{N} 1} / t_{\mathrm{N} 0}\right)\right)$

$G(\rho)$ : increasing function of $\rho$ which satisfies $G(0)=0$

$H$ : plastic strain term in yield function $\left(=(-\Delta e)^{\mathrm{p}}=\left(1+e_{0}\right) \varepsilon_{\mathrm{v}}^{\mathrm{p}}\right)$

$I_{1}, I_{2}$, and $I_{3}$ : first, second and third invariants of $\sigma_{\mathrm{ij}}$

$I_{\mathrm{r} 1}, I_{\mathrm{r} 2}$ and $I_{\mathrm{r} 3}$ : first, second and third invariants of $r_{\mathrm{ij}}$ (where $r_{\mathrm{ik}} r_{\mathrm{kj}}=\sigma_{\mathrm{ij}}$ )

$N$ : void ratio at the NCL for $p=98 \mathrm{kPa}$ (at $(-\dot{e})^{\mathrm{p}}=(-\dot{e})_{\mathrm{ref}}^{\mathrm{p}}$ in case of time-dependent model)

$Q(\omega)$ : increasing function of $\omega$ which satisfies $Q(0)=0$

$R_{\mathrm{CS}}$ : principal stress ratio at critical state in triaxial compression $\left(=\left(\sigma_{1} / \sigma_{3}\right)_{\mathrm{CS}(\mathrm{comp})}\right)$

$X:$ stress ratio $\left(=t_{\mathrm{S}} / t_{\mathrm{N}}\right)$

$Y$ : plastic strain increment ratio $\left(=d \varepsilon_{\mathrm{N}}^{* \mathrm{p}} /\right.$ $\left.d \varepsilon_{\mathrm{S}}^{* \mathrm{p}}\right)$

$\beta$ : material parameter to determine the shape of the yield surface

$\delta_{\mathrm{ij}}$ : unit tensor

$\phi_{\text {moij }}$ : mobilized angle between two principal stresses $\left(\sigma_{\mathrm{i}}\right.$ and $\left.\sigma_{\mathrm{j}}\right)$

$\varepsilon_{1}, \varepsilon_{2}$ and $\varepsilon_{3}$ : principal strains

$\varepsilon_{\mathrm{ij}}$ : strain tensor

$\varepsilon_{\mathrm{d}}$ : deviatoric strain

$\varepsilon_{\mathrm{v}}$ : volumetric strain

$\eta:$ stress ratio $(=q / p)$

$\varphi_{1}$ and $\varphi_{2}$ : principal values of the fabric tensor

$\kappa$ : swelling index

$\lambda$ : compression index

$\lambda_{\mathrm{k}}$ : coefficient for considering influence of void ratio on permeability

$\lambda_{\alpha}$ : coefficient of secondary consolidation

$v_{\mathrm{e}}$ : Poisson's ratio of elastic component

$\rho$ : state variable representing density-difference between the current void ratio and the void ratio on the NCL at the same stress level

$\sigma_{1}, \sigma_{2}$ and $\sigma_{3}:$ principal stresses

$\sigma_{\mathrm{ij}}:$ stress tensor

$\sigma_{\mathrm{ij}}^{*}$ : modified stress tensor defined by Satake

$\omega$ : state variable considering the bonding effect as an imaginary increase of density

$\psi$ : state variable for shifting the NCL on the $e-\ln t_{\mathrm{N} 1}$ plane

$\zeta(\eta), \zeta(X)$ : increasing function of the stress ratio $(\eta$ or $X$ ) which satisfies $\zeta(0)=0$-i.e., function to determine the shape of yield surface

1: proportionality constant $\left(=d F / h^{\mathrm{p}}\right.$ or $\left.(d F+\mathrm{d} \psi) / h^{\mathrm{p}}\right)$

$M$ : stress ratio $\eta$ at the critical state

$M^{*}$ : intercept with $X$ axis in stress-dilatancy relation based on the $t_{\mathrm{ij}}$ concept-determined from $X_{\mathrm{CS}}$ and $Y_{\mathrm{CS}}$

superscript $e$ : elastic component superscript $p$ : plastic component subscript 0: initial value 
subscript ref: value at reference state subscript (equ): equivalent value subscript $C S$ : value at critical state subscript $N C$ : value at normally consolidated state overhead dot $(\cdot)$ : rate of quantities prefix $d$ : infinitesimal increment of quantities prefix $\Delta$ : finite change in quantities

\section{REFERENCES}

1) Asaoka, A., Nakano, M. and Noda, T. (1997): Soil-water coupled behavior of heavily overconsolidated clay near/at critical state, Soils and Foundations, 37(1), 13-28.

2) Asaoka, A., Nakano, M. and Noda, T. (2000a): Superloading yield surface concept for highly structured soil behavior, Soils and Foundations, 40(2), 99-110.

3) Asaoka, A., Nakano, M. and Noda, T. (2000b): Elasto-plastic behaviour of structured over consolidated soils, Jour. of Appli. Mech., JSCE, 3, 335-342 (in Japanese).

4) Asaoka, A. (2003): Consolidation of clay and compaction of sand-an elastoplastic description, Proc. of 12th Asian Regional Conf. on Soil Mech. and Geotechnical Eng., Keynote Paper, Singapore, 2, 1157-1195.

5) Chowdhury, E. Q. and Nakai, T. (1998): Consequence of the $t_{\mathrm{ij}}{ }^{-}$ concept and a new modeling approach, Computers and Geotechnics, 23(3), 131-164.

6) Graham, J., Crooks, J. H. A. and Bell, A. L. (1983): Time-effects on the stress-strain behavior of natural soft clays, Geotechnique, 33(3), 327-340.

7) Hashiguchi, K. (1980): Constitutive equation of elastoplastic materials with elasto-plastic transition, Jour. of Appli. Mech., ASME, 102(2), 266-272.

8) Kikumoto, M., Nakai, T. and Kyokawa, H. (2009): New description of stress-induced anisotropy using modified stress, Proc. of 17th International Conf. on Soil Mech. and Geotechnical Eng., 1, 550-553.

9) Leroueil, S. and Marques, M. E. S. (1996): Importance of strain rate and temperature effect in geotechnical engineering, Measuring and Modeling Time Dependent Soil Behavior, Geotechnical Special Publication, ASCE, 61, 1-60.

10) Maeda, K., Hirabayashi, H. and Ohmura, A. (2006): Micromechanical influence of grain properties on deformation-failure behaviors of granular media by DEM. Proc. of Geomechnics and Geotechnics of Particulate Media, 173-179.

11) Matsuoka, H. and Nakai, T. (1974): Stress-deformation and strength characteristics of soil under three different principal stresses, Proc. of JSCE, 232, 59-70.

12) Nakai, T. and Matsuoka, H. (1983): Shear behaviors of sand and clay under three-dimensional stress condition, Soils and Foundations, 23(2), 26-42.

13) Nakai, T. and Mihara, Y. (1984): A new mechanical quantity for soils and its application to elastoplastic constitutive models, Soils and Foundations, 24(2), 82-94.

14) Nakai, T. and Matsuoka, H. (1986): A generalized elastoplastic constitutive model for clay in three-dimensional stresses, Soils and Foundations, 26(3), 81-98.

15) Nakai, T. (1989): An isotropic hardening elastoplastic model for sand considering the stress path dependency in three-dimensional stresses, Soils and Foundations, 29(1), 119-137.

16) Nakai, T. and Hinokio, T. (2004): A simple elastoplastic model for normally and over consolidated soils with unified material parameters, Soils and Foundations, 44(2), 53-70.

17) Nakai, T. (2007): Modeling of soil behavior based on $t_{\mathrm{ij}}$ concept, Proc. of 13th Asian Regional Conf. on Soil Mech. and Geotechnical Eng., Keynote Paper, Kolkata, 2, 69-89.

18) Nakai, T., Kyokawa, H., Kikumoto, M. and Zhang, F. (2009): Elastoplastic modeling of geomaterials considering the influence and density and bonding, Proc. of Prediction and Simulation Methods for Geohazard Mitigation, 367-373.
19) Nakai, T., Shahin, H. M., Kikumoto, M., Kyokawa, H., Zhang, F. and Farias, M. M. (2011): A simple and unified one-dimensional model to describe various characteristics of soils, Soils and Foundations, 51(6), 1129-1148.

20) Oda, M. (1972): The mechanism of fabric changes during compressional deformation of sand. Soils and Foundations, 12(2), 1-18.

21) Oka, F., Kodaka, T., Kimoto, S., Ishigaki, S. and Tsuji, C. (2003): Step-changed strain rate effects on the stress-strain relations of clay and a constitutive modeling, Soils and Foundations, 43(4), 189-202.

22) Pedroso, D. M., Farias, M. M. and Nakai, T. (2005): An interpretation of subloading $t_{\mathrm{ij}}$ model in the context of conventional elastoplasticity theory, Soils and Foundations, 45(4), 61-77.

23) Roscoe, K. H. and Burland, J. B. (1968): On the generalized stressstrain behavior of wet clay. Heyman and F. A. Leckie (eds.), Engineering Plasticity, Cambridge University Press, 535-609.

24) Satake, M. (1982): Fabric tensor in granular materials. Proc. of IUTAM Conference on Deformation and Failure of Granular Materials, Delft, 63-68.

25) Satake, M. (1984): Anisotropy in ground and soil materials, Tsuchi to Kiso, 32(11), 5-12 (in Japanese).

26) Schofield, A. N. and Wroth, C. P. (1968): Critical State Soil Mechanics, McGrow-Hill, London.

27) Sekiguchi, H. (1984): Theory of undrained creep rupture of normally consolidated clay based on elasto-viscoplasticity, Soils and Foundations, 24(1), 129-147.

\section{APPENDIX I: PARTIAL DERRIVATIVES OF STRESS FUNCTION $\boldsymbol{F}$ AND STRESS VARIABLES}

The stress term $F$ in the models based on the $t_{\mathrm{ij}}$-concept is expressed by the following form as a function of the mean stress $t_{\mathrm{N}}$ and the stress ratio $X$ :

$$
F=(\lambda-\kappa)\left\{\ln \frac{t_{\mathrm{N}}}{t_{\mathrm{N} 0}}+\zeta(X)\right\}
$$

and the definitions of tensors and scalars related to the $t_{\mathrm{ij}}{ }^{-}$ concept are shown in Table 1.

Firstly, the derivatives of $F$ with respect to modified stress $t_{\mathrm{ij}}$ are shown.

$$
\begin{aligned}
& \frac{\partial F}{\partial t_{\mathrm{ij}}}=\frac{\partial F}{\partial t_{\mathrm{N}}} \frac{\partial t_{\mathrm{N}}}{\partial t_{\mathrm{ij}}}+\frac{\partial F}{\partial X} \frac{\partial X}{\partial t_{\mathrm{ij}}} \\
& \frac{\partial F}{\partial t_{\mathrm{N}}}=(\lambda-\kappa) \frac{1}{t_{\mathrm{N}}} \\
& \frac{\partial t_{\mathrm{N}}}{\partial t_{\mathrm{ij}}}=\frac{\partial\left(t_{\mathrm{k} 1} a_{\mathrm{kl}}\right)}{\partial t_{\mathrm{ij}}}=a_{\mathrm{ij}} \\
& \frac{\partial F}{\partial X}=(\lambda-\kappa) \zeta^{\prime}(X) \\
& \frac{\partial X}{\partial t_{\mathrm{ij}}}=\frac{\partial\left(\sqrt{x_{\mathrm{k}} x_{\mathrm{kl}}}\right)}{\partial x_{\mathrm{mn}}} \frac{\partial x_{\mathrm{mn}}}{\partial t_{\mathrm{ij}}}=\frac{1}{X \cdot t_{\mathrm{N}}}\left(x_{\mathrm{ij}}-X^{2} a_{\mathrm{ij}}\right)
\end{aligned}
$$

As described in previous papers (e.g., Nakai and Mihara, 1984; Nakai, 1989), the mean stress $t_{\mathrm{N}}$ and the stress ratio $X$ are also given using the ordinary stress $\sigma_{\mathrm{ij}}$ as $t_{\mathrm{N}}=$ $3 I_{3} / I_{2}, X=\sqrt{I_{1} I_{2} / 9 I_{3}-1}$. Then, the derivative of $F$ with respect to the ordinary stress $\sigma_{\mathrm{ij}}$ is expressed as follows:

$$
\begin{aligned}
& \frac{\partial F}{\partial \sigma_{\mathrm{ij}}}=\frac{\partial F}{\partial t_{\mathrm{N}}} \frac{\partial t_{\mathrm{N}}}{\partial \sigma_{\mathrm{ij}}}+\frac{\partial F}{\partial X} \frac{\partial X}{\partial \sigma_{\mathrm{ij}}} \\
& \frac{\partial t_{\mathrm{N}}}{\partial \sigma_{\mathrm{ij}}}=\frac{\partial}{\partial \sigma_{\mathrm{ij}}}\left(3 \frac{I_{3}}{I_{2}}\right)
\end{aligned}
$$




$$
\frac{\partial X}{\partial \sigma_{\mathrm{ij}}}=\frac{\partial}{\partial \sigma_{\mathrm{ij}}}\left(\sqrt{\frac{\mathrm{I}_{1} I_{2}}{9 I_{3}}-1}\right)
$$

where, $I_{1}, I_{2}$ and $I_{3}$ are the first, second and third invariants of $\sigma_{\mathrm{ij}}$, as shown in Eq. (25).

\section{APPENDIX II: ANOTHER THREE-DIMENSIONAL FORMULATION}

The yield function $f=0$ and the consistency condition $d f=0$ are given by:

$$
\begin{aligned}
& f=F-\left\{H+\left(\rho_{0}-\rho\right)+\left(\psi_{0}-\psi\right)\right\}=0 \\
& F=(\lambda-\kappa) \ln \frac{t_{\mathrm{N} 1}}{t_{\mathrm{N} 0}}=(\lambda-\kappa)\left\{\ln \frac{t_{\mathrm{N}}}{t_{\mathrm{N} 0}}+\varsigma(X)\right\} \\
& H=(-\Delta e)^{\mathrm{p}}=\left(1+e_{0}\right) \cdot \varepsilon_{\mathrm{v}}^{\mathrm{p}} \\
& d f=d F-\{d H-d \rho-d \psi\} \\
& =d F-\left\{d(-e)^{\mathrm{p}}-d \rho-d \psi\right\} \\
& =d F-\left\{\left(1+e_{0}\right) \Lambda \frac{\partial F}{\partial t_{\mathrm{ii}}}-d \rho-d \psi\right\}=0
\end{aligned}
$$

Now, in the one-dimensional model (Nakai et al., 2011), $d \rho$ is expressed as

$$
d \rho=-\{G(\rho)+Q(\omega)\} \cdot d(-e)^{\mathrm{p}}
$$

Under isotropic compression $\left(d \varepsilon_{1}^{\mathrm{p}}=d \varepsilon_{2}^{\mathrm{p}}=d \varepsilon_{3}^{\mathrm{p}}\right)$, there is the following relation between $d(-e)^{\mathrm{p}}$ and $\Lambda$ :

$$
\begin{aligned}
d(-e)^{\mathrm{p}} & =\left(1+e_{0}\right) d \varepsilon_{\mathrm{v}}^{\mathrm{p}}=\sqrt{3}\left(1+e_{0}\right)\left\|d \varepsilon_{\mathrm{ij}}^{\mathrm{p}}\right\| \\
& =\sqrt{3}\left(1+e_{0}\right) \Lambda\left\|\frac{\partial F}{\partial t_{\mathrm{ij}}}\right\|
\end{aligned}
$$

Assuming that the evolution rule of $\rho$ in general stress conditions is given by replacing $d(-e)^{\mathrm{p}}$ in Eq. (A14) with $\sqrt{3}\left(1+e_{0}\right) \Lambda\left\|\partial F / \partial t_{\mathrm{ij}}\right\|$, Eq. (A13) can be rewritten as:

$$
\begin{aligned}
d f= & d F-\left(1+e_{0}\right) \frac{\partial F}{\partial t_{\mathrm{kk}}} \Lambda-\left\{\sqrt{3}\left(1+e_{0}\right)\left\|\frac{\partial F}{\partial t_{\mathrm{ij}}}\right\|\right\} G(\rho) \Lambda \\
& -\left\{\sqrt{3}\left(1+e_{0}\right)\left\|\frac{\partial F}{\partial t_{\mathrm{ij}}}\right\|\right\} Q(\omega) \Lambda+d \psi=0
\end{aligned}
$$

Then, the proportional constant $\Lambda$ is given by

$$
\begin{aligned}
\Lambda & =\frac{d F+d \psi}{\left(1+e_{0}\right)\left\{\frac{\partial F}{\partial t_{\mathrm{kk}}}+\sqrt{3}\left\|\frac{\partial F}{\partial t_{\mathrm{ij}}}\right\| G(\rho)+\sqrt{3}\left\|\frac{\partial F}{\partial t_{\mathrm{ij}}}\right\| Q(\omega)\right\}} \\
& =\frac{d F+d \psi}{h^{\mathrm{p}}}
\end{aligned}
$$
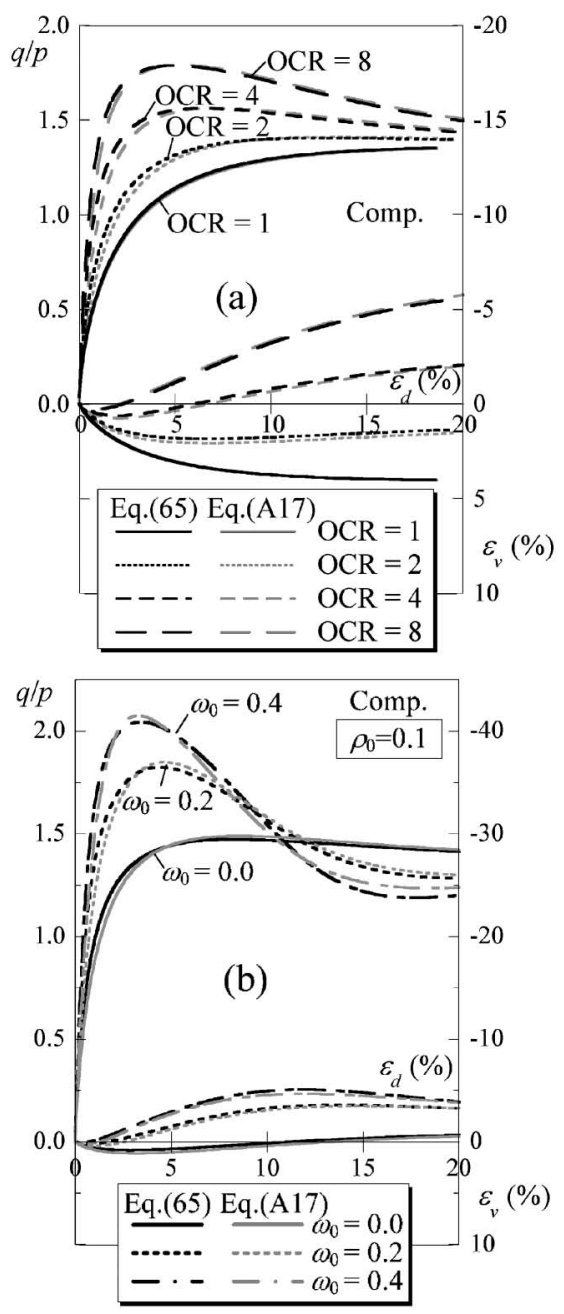

Fig. A1. Comparison of calculated stress-strain curves using $\Lambda$ from Eq. (65) and $\Lambda$ from Eq. (A17)

Figure A1 shows the comparison of the calculated results (black curves) in Figs. 21(a) and 25(a) using $\Lambda$ from Eq. (65) with the corresponding results (gray curves) using $\Lambda$ from Eq. (A17). Here, diagram (a) shows the results for different initial density (OCR) without bonding $\left(\omega_{0}=0\right)$, and diagram (b) shows the results for different initial bonding $\left(\omega_{0}\right)$ under the same initial density $\left(\rho_{0}=0.1\right)$. Although the form of the equations for $G(\rho)$ and $Q(\omega)$ in Eq. (A17) are the same as Eqs. (54) and (60), the values of material parameters $a$ and $b$ in Eq. (A17) are $a=90$ and $b=7$. It can be seen that there is not much difference in the calculated results either using Eq. (65) or Eq. (A17). 